\title{
Opportunities and Challenges for Nanotherapeutics for the Aging Population
}

\author{
Nicholas J. Hunt ${ }^{1,2,3,4 *}$, Peter A. G. McCourt ${ }^{3,5}$, Zdenka Kuncic ${ }^{4,6}$, David G. Le Couteur ${ }^{1,2,3}$ \\ and Victoria C. Cogger ${ }^{1,2,3 *}$
}

${ }^{1}$ ANZAC Research Institute, Ageing and Alzheimer's Institute and Centre for Education and Research on Ageing, Concord Repatriation General Hospital, Concord, NSW, Australia, ${ }^{2}$ Faculty of Medicine and Health, The University of Sydney, Camperdown, NSW, Australia, ${ }^{3}$ Charles Perkins Centre, The University of Sydney, Camperdown, NSW, Australia, ${ }^{4}$ Sydney Nano Institute, The University of Sydney, Camperdown, NSW, Australia, ${ }^{5}$ Department of Medical Biology, University of Troms $\varnothing-$ The Arctic University of Norway, Tromsø, Norway, ${ }^{6}$ School of Physics, The University of Sydney, Sydney, NSW, Australia

OPEN ACCESS

Edited by:

Vijayakumar Sekar,

Shandong University, China

Reviewed by:

Di Huang,

Massachusetts Eye and Ear Infirmary and Harvard Medical School,

United States

Silvana Alborés,

Universidad de la República, Uruguay Mary Cano-Sarabia,

Catalan Institute of Nanoscience and Nanotechnology (CIN2), Spain

${ }^{*}$ Correspondence:

Nicholas J. Hunt nick.hunt@sydney.edu.au Victoria C. Cogger victoria.cogger@sydney.edu.au

Specialty section:

This article was submitted to Biomedical Nanotechnology,

a section of the journal

Frontiers in Nanotechnology

Received: 09 December 2021 Accepted: 03 January 2022 Published: 25 January 2022

Citation:

Hunt NJ, McCourt PAG, Kuncic Z, Le Couteur DG and Cogger VC (2022)

Opportunities and Challenges for

Nanotherapeutics for the Aging Population.

Front. Nanotechnol. 4:832524. doi: 10.3389/fnano.2022.832524
Nanotherapeutics utilize the properties of nanomaterials to alter the pharmacology of the drugs and therapies being transported, leading to changes in their biological disposition (absorption, distribution, cellular uptake, metabolism and elimination) and ultimately, their pharmacological effect. This provides an opportunity to optimize the pharmacology of drugs, particularly for those that are dependent on hepatic action. Old age is associated with changes in many pharmacokinetic processes which tend to impair drug efficacy and increase risk of toxicity. While these age-related changes are drug-specific they could be directly addressed using nanotechnology and precision targeting. The benefits of nanotherapeutics needs to be balanced against toxicity, with future use in humans dependent upon the gathering of information about the clearance and long-term safety of nanomaterials.

Keywords: drug delivery and targeting, ADME and toxicity, nano, ageing, clinical challenges, quantum dot, solid lipid nanoparticle, pharmaceuical

\section{INTRODUCTION}

The use of nanotechnology in medicine is a rapidly emerging area. In 2016, Anselmo and Mitragotri (2016) highlighted the clinical landscape of nanotherapeutics which included over 25 FDA approved nanotechnologies and 45 that were in clinical trials. By 2019, there were 50 nanotherapeutic formulations available for patient care, including cancer treatments, iron-replacement therapies, contrast agents and vaccines (Anselmo and Mitragotri, 2019). In addition, there were 90 clinical trials of nanomedicines which included 15 new nanotechnologies (Anselmo and Mitragotri, 2019). Following this, the emergence of lipid nanoparticles (NPs) for vaccine delivery in response to COVID-19 (Shin et al., 2020; Khurana et al., 2021) has delivered the shot-in-the-arm nanotherapeutics needed to demonstrate their broader potential.

The goal of nanotherapeutics or nano-drug delivery is to develop next generation therapies that have increased: safety; biocompatibility; bioavailability; therapeutic action and bio-adherence; and

Abbreviations: Alb, albumin; ABC, ATP-binding cassette; DC, dendritic cell; FSA, formaldehyde treated serum albumin; GI, gastrointestinal; GFR, glomerular filtration rate; KC, Kupffer cells; LSEC, liver sinusoidal endothelial cells; MPS, mononuclear phagocytic system; NP, nanoparticle; P-gp, P-glycoprotein; QD, quantum dot; SLC, solute carriers; SLCO, solute carrier organic anion; SLN, solid lipid nanoparticles. 
TABLE 1 | Summary of the changes with aging on drug deposition and the effect on nanotherapeutics.

\begin{tabular}{|c|c|c|}
\hline Feature & Change with aging & Effect on nanotherapeutics \\
\hline \multicolumn{3}{|l|}{ Absorption } \\
\hline Gastric acid & Decreased secretion Hilmer. (2008) & Reduced degradation Bi et al. (2020) \\
\hline Gut motility & Delayed gastric emptying Klotz. (2009) & Increased absorption time Bi et al. (2020) \\
\hline Microbiota & Reduced diversity and leaky gut Walrath et al. (2021) & Potential increase in toxicity Bi et al. (2020) \\
\hline Injectable & Injection absorbance unaffected Heise et al. (2017) & Injectable NPs are unaffected Pardi et al. (2015) \\
\hline \multicolumn{3}{|l|}{ Permeability } \\
\hline Passive & Unaffected Yuasa et al. (1997) & Unaffected Bi et al. (2020), Hunt et al. (2021) \\
\hline Solute transporters & $\begin{array}{l}\text { Reduction in OCT transporters, P-gp unaffected in gut Warrington et al. (2004), } \\
\text { Jang et al. (2016) }\end{array}$ & $\begin{array}{l}\text { NPs are absorbed by a broader range of transporters Hunt et al. } \\
\text { (2020), Hunt et al. (2021) }\end{array}$ \\
\hline $\begin{array}{c}\text { 1st pass } \\
\text { metabolism }\end{array}$ & Decreased due to reduced blood flow Mclean and Le Couteur. (2004) & Prolonged circulation time Hunt et al. (2021) \\
\hline \multicolumn{3}{|l|}{ Distribution } \\
\hline Plasma proteins & Reduced circulating albumin Klotz. (2009) & May reduce protein corona \\
\hline Body composition & Decreased water content, increased fat content Mclean and Le Couteur. (2004) & $\begin{array}{l}\text { May reduced distribution of water-soluble NPs, increased } \\
\text { distribution of fat-soluble NPs }\end{array}$ \\
\hline \multicolumn{3}{|l|}{ Cell uptake } \\
\hline $\begin{array}{l}\text { Complement } \\
\text { proteins }\end{array}$ & $\begin{array}{l}\text { Reduced circulating lgG, increased classical and alternative complement } \\
\text { cascades Gaya Da Costa et al. (2018), Gudelj et al. (2018) }\end{array}$ & $\begin{array}{l}\text { Potential change in NP opsonisation in elderly La-Beck et al. } \\
(2021)\end{array}$ \\
\hline Phagocytosis & $\begin{array}{l}\text { Reduced clearance, but with increased number and circulating inflammatory } \\
\text { markers Hunt et al. (2019) }\end{array}$ & Unaffected MPS uptake Pomatto et al. (2018) \\
\hline Endocytosis & By LSECs is slightly reduced Simon-Santamaria et al. (2010) & Largely unaffected Hunt et al. (2020) \\
\hline Transcytosis & By LSECs is unaffected Simionescu et al. (2009) & Unaffected Hunt et al. (2020) \\
\hline Passive uptake & Decreased due to pseudocapillarization Le Couteur et al. (2008) & Reduced NP uptake Hunt et al. (2021) \\
\hline \multicolumn{3}{|l|}{ Metabolism } \\
\hline Phase I & Reduced (due to hepatic blood flow) Mclean and Le Couteur. (2004) & Prolonged circulation time Hunt et al. (2021) \\
\hline Phase II & Reduced Mclean and Le Couteur. (2004) & Unaffected Pomatto et al. (2018) \\
\hline \multicolumn{3}{|l|}{ Clearance } \\
\hline $\begin{array}{l}\text { Passive renal } \\
\text { elimination }\end{array}$ & $\begin{array}{l}\text { Decreased GFR and increased renal vascular resistance Mclean and Le Couteur. } \\
\text { (2004) }\end{array}$ & Potentially unaffected Pinheiro et al. (2019) \\
\hline $\begin{array}{l}\text { Active renal } \\
\text { elimination }\end{array}$ & $\begin{array}{l}\text { Decreased P-gp, OCT2 and MATE soluble transport Warrington et al. (2004), Xu } \\
\text { et al. (2017) }\end{array}$ & May decreased NP clearance via P-gp and MATE \\
\hline Biliary elimination & $\begin{array}{l}\text { Decreased xenobiotic elimination due to decreased soluble transporters (Xu et al., } \\
\text { 2017) }\end{array}$ & Decreased NP clearance Pinheiro et al. (2019) \\
\hline
\end{tabular}

reduced: dosage, clearance and metabolism (Sahoo et al., 2007). Nanoscale formulations have facilitated advanced engineering of drug pharmacology in order to optimize drug release, absorption, site-directed distribution, metabolism and excretion, and drug residence time (Suk et al., 2016; Patra et al., 2018). These advances have been strongly mediated by PEGylation of nanotherapeutics and drugs to prolong their circulation time, and delay immune recognition and metabolism (Suk et al., 2016).

Next generation advances include sensor-based drug release, targeting to intracellular compartments, improved modelling and screening of nanotechnology platforms, and the application of nanotechnology to a broader range of therapeutic classes including proteins, DNA, siRNA and miRNA (Sindhwani and Chan, 2021). These recent advances have highlighted that nanomaterials have broad impacts on drug absorption, distribution, metabolism and excretion, and the importance of framework for their regulation (Zolnik and Sadrieh, 2009). However, these studies have also highlighted that nanotherapeutics in aged cohorts are rarely investigated.

This presents a critical problem as the most common user of drug therapeutics are the older (60+ years) population (Martin et al., 2019). This problem exists for many drug therapeutics with older patients rarely participating in clinical trials and proposed to limit the efficacy once translated to the clinic (Shenoy and
Harugeri, 2015). With $85 \%$ of adults over 60 years taking at least one medication (Martin et al., 2019) and two-thirds of these using 4 or more drugs (Elliott, 2006) this highlights that therapeutics, including nanotherapeutics, will primarily be given to this older age bracket.

Aging promotes changes in the pharmacokinetics and pharmacodynamics of nearly all medications in a drug dependent way (Klotz, 2009; Reeve et al., 2015; Khan and Roberts, 2018). In the case of nanotherapeutics this may impede the advantages that a nanomaterial might have on the disposition of a therapeutic agent. On the other hand, nanotherapeutics could be designed to overcome age-related changes in pharmacokinetics that can impair the efficacy of drugs in older people. The aim of this review is to provide an overview of the broad changes in drug absorption, distribution, cellular uptake, metabolism, drug action and removal facilitated by nanomaterials (summarized in Table 1). Then, we describe how these effects may offset age-related changes in the disposition of drugs and mitigate off target effects by precision drug delivery.

Administrative route of nanotherapeutic studies: mixed (Pardi et al., 2015); oral (Bi et al., 2020; Hunt et al., 2020; Hunt et al., 2021), IP injection (Weitzmann et al., 2015; Pinheiro et al., 2019) and inhalation: (Pomatto et al., 2018). 


\section{ABSORPTION}

Nanotherapeutics administration can occur in several ways. When given orally, absorption occurs via the stomach and gastrointestinal (GI) tract. Subcutaneous or intraperitoneal delivered therapeutics are taken up via the circulation, and those that are intravenously injected are placed directly into the systemic circulation. Bioavailability is the fraction that reaches the systemic circulation-by definition drugs given via intravenous injection will have $100 \%$ bioavailability.

The kinetics of lipid NPs with a payload of mRNA were studied when given via multiple injection techniques (intramuscular, subcutaneous, intraperitoneal, intravenous or intradermal) (Pardi et al., 2015). Systemic uptake and distribution were rapid with all these routes of administration. A key difference, was that intravenous injections recorded a $\mathrm{C}_{\max }$ (peak concentration) 10-fold higher than all other injection methods with $\mathrm{T}_{\max }$ (time to reach peak) occurring at the same time point for all methods of administration. Intravenous injections demonstrated the shortest half-life by 2 -fold compared to subcutaneous and intraperitoneal and 3-fold compared to intramuscular and intradermal injections (Pardi et al., 2015).

The evaluation of the oral absorption of nanotherapeutics has been performed with in vitro and in vivo methods. The results show that it is important to perform multiple methods to determine the bioavailability fraction within initial nanomedicine research (Faria et al., 2018). The absorption of orally administrated nanomaterials through the GI tract is facilitated by Peyer's Patches or aggregated lymphoid nodules, $\mathrm{M}$ cells and enterocytes (Schimpel et al., 2014). Lymph draining patches have been observed to promote uptake of a range of different sized nanomaterials (alginate coated chitosan NPs and polymeric NPs) from $50 \mathrm{~nm}$ to $200 \mu \mathrm{m}$ and have been investigated for immune modulation strategies, however, absorption via lymphatics doesn't equate to improved bioavailability (Borges et al., 2006; Des Rieux et al., 2006). Finally, Yao et al. (2015) used Au NPs to demonstrated intestinal enterocytes can take up more limited range of nanomaterials $(50-500 \mathrm{~nm})$ with uptake increasing with reductions in NP size.

Enterocyte uptake has been extensively evaluated using Caco-2 cells for metal NPs (Imai et al., 2017), organics (Behrens et al., 2002; Coyuco et al., 2011), dendrimers (Kitchens et al., 2007) and solid lipid nanoparticles (SLN) (Chai et al., 2016). Caco-2 cells and co-cultures of Caco-2/ HT29-MTX (enterocyte, mucus-secreting goblet and M cells) are utilized to visualize and measure the dynamics of NP transfer (Schimpel et al., 2014). To further understand these pathways the use of endocytosis inhibitors has demonstrated that the uptake of metals, organics, dendrimers and SLN is via multiple specific and non-specific pathways. For example, the uptake of SLN and dendrimers, are mediated by macropinocytosis, clathrin- and caveolin-mediated endocytosis (Kitchens et al., 2007; Chai et al., 2016). These endocytosis and transcytosis pathways are forms of active transport within the GI tract but also the liver; here they are responsible for the direct remove of systemically circulating nanomaterials (discussed in Distribution).

In our previously study, Hunt et al. (2020) utilized small intestine explants to study the uptake of NPs. Explants allow uptake to be studied with the ease and flexibility of in vitro cell cultures but have greater similarity to the in vivo environment (Kothari and Rajagopalan, 2019). Using explants, we found that metal $\left(\mathrm{Ag}_{2} \mathrm{~S}\right)$ quantum dots (QDs) were non-specifically taken up into small intestine explants and were blocked by inhibitors acting on macropinocytosis, and clathrin- and caveolinmediated endocytosis (Hunt et al., 2020). Coating the surface of these QDs with various polymers facilitated receptor specific endocytosis pathways. We subsequently determined the in vivo bioavailability of conventional and polymer coated QDs, and found that these results reflected those found in the explant studies (Hunt et al., 2020).

These studies highlight that nanomaterials are not passively absorbed, but actively taken up by multiple transporters. This pathway is not unique to nanomaterials with drugs, and more broadly xenobiotics are heavily dependent on active transport channels, particularly solute carriers (SLC) and solute carrier organic anion (SLCO) superfamilies of membrane transporters (Döring and Petzinger, 2014).

Targeting of specific nutrient transporters (SLC5A6, SCL10A2, and SLC22A5) via the use of surface coatings, NP formulations and selective dendrimers has been extensively investigated to improve the oral bioavailability of nanotherapeutic drug delivery platforms (Kou et al., 2018). Utilizing biotin, deoxycholic acid, tetra DOCA, taurocholic acid and L-carnitine multiple groups have shown improved bioavailability of oral insulins and heparin (Lee et al., 2001; Lee et al., 2005; Lee et al., 2006; Kim et al., 2007; Khatun et al., 2013; Alam et al., 2014; Zhang et al., 2014). These groups observed that both the drug delivered, and the materials used are rapidly distributed to the liver and metabolized following absorption. This critically demonstrates the potential use of these drug delivery platforms for targeting hepatic drug receptors.

Recently there has been increasing interest in the effects of the gut microbiota on the metabolism of xenobiotics (including NPs). Microbiota facilitate metabolism via azo reduction, amide formation, hydrolysis, acetylation, nitro reduction, deamination, sulfoxide/oxide reduction and thiazide ring formation (Jourova et al., 2016). Degradation of Ag NPs has been extensively examined and dependent on gastric $\mathrm{pH}$ and the microbiome (Bi et al., 2020). There are complex multi-directional relationships between Ag NPs (particularly those with a diameter less than $10 \mathrm{~nm}$ ), the intestinal microbiota, and the epithelial mucus. NPs increase mucosal secretions which limit their interactions between the cell membrane and inhibit uptake. Ag NPs may also directly impact on the composition of the microbiome, decreasing Firmicutes and Lactobacillus populations (Bi et al., 2020).

\section{Absorption and Aging}

Aging is associated with impeded oral absorption of drugs and changes in their pharmacokinetic profile (Vinarov et al., 2021). 
This is due to several factors, primarily due to decreased blood flow to most organs including the mesenteric system which contributes to the delayed absorption of drugs and metabolites observed in elderly patients. Critically for injected materials, older patients demonstrate similar pharmacodynamic responses to younger patients (e.g., fast acting insulin), which indicates there are no age-related changes in injectable absorption (Heise et al., 2017).

Modification of GI metabolism in older patients delays absorption of drugs, metabolites and xenobiotics. Passive intestinal transport of most substances in not considered to be affected by aging (Yuasa et al., 1997; Saltzman and Russell, 1998), yet active transportation via solute transporters (SLCs and SLCOs) has been shown to be impacted by aging. As reviewed by Hilmer (2008) the active transportation of glucose, calcium and Vitamin B12 are all observed to decrease with aging in rats.

Active transport of drugs, NPs and xenobiotics are heavily dependent on solute carriers and mucin-adhesion (Döring and Petzinger, 2014; Marczynski et al., 2021) with age-related reduction in secretory mucins and altered glycan profiles impede transport via solute carriers (Kameyama et al., 2021). In the rodent GI tract old age is not associated with changes in enzyme $\mathrm{P} 450$ (CYP3A4) or the soluble transporter p-glycoprotein (P-gp/ABCB1/MDR1) (Warrington et al., 2004). Together these results suggest that those drugs and xenobiotics that are actively transported by SLCOs such as OCT1 (e.g., metformin) have impaired absorption in older patients (Jang et al., 2016). Comparatively, carbon NPs coated with carboxylic acid demonstrate uptake via P-gp (Coyuco et al., 2011) and may not be affected by changes with age. Finally, Hunt et al. (2021) investigated the uptake of QD capped with carboxylic acid and conjugated metformin in aging mice. In old mice there was a decreased uptake of metformin, with attachment to QDs preventing this decline. Inhibitor studies showed there were agerelated changes in the soluble transporters that mediated absorption of metformin.

Drug absorption can also be influenced by age-related changes in gastric $\mathrm{pH}$. There is a $20-25 \%$ reduction in gastric acid secretion in old age, leading to increased gastric $\mathrm{pH}$. These aging changes are compounded by agerelated changes in diet and increased use of medications such as protein pump inhibitors (Hilmer, 2008; Reeve et al., 2017; An et al., 2018). Gastric acid is a critical barrier for nanotherapeutics due to the risk of degradation of the transported drug (Tyagi et al., 2018). Improved yields for nanotherapeutics may occur in older people secondary to the reduction in gastric acid secretions. In mice, pretreatment with a protein pump inhibitor to increase gastric $\mathrm{pH}$, increased 3-fold the oral bioavailability of growth hormone in liposomes (Parmentier et al., 2014). As well as changes in gastric $\mathrm{pH}$, there is age-related reduction in gut motility that delays gastric emptying, generally prolonging $\mathrm{T}_{\max }$ and decreasing $\mathrm{C}_{\max }$ rather than altering overall absorption (Holt, 2007; Saffrey, 2014).

Aging is associated with increased leakiness of the gastrointestinal epithelial barrier and changes in the microbiota (Walrath et al., 2021). In humans, there is a high degree of variability due to diet and drugs (Claesson et al., 2011), however it has usually been reported that old age is associated with reduced microbial diversity (Bischoff, 2016), decreased Firmicutes and increased Proteobacteria (Walrath et al., 2021). Changes in gut microbiome contribute to decreased bacterial short chain fatty acids, increased lipopolysaccharides and decreased secondary bile acid production. This leads to degradation of the intestinal barrier observed with aging, called the leaky gut model of aging and inflammation (Mäkivuokko et al., 2009; Bischoff, 2016; Walrath et al., 2021). The 'leaky gut' may pose a broader challenge to orally administrated nanotherapeutics due to its potential effects on passive diffusion and inflammation within the gut wall and lumen (Figure 1).

\section{DISTRIBUTION}

Distribution refers to the accumulation within peripheral compartments or the steady state concentration at the site of action relative to the concentration in the circulation. The effect of drug distribution on blood levels of a drug is usually seen after the effects of absorption, bioavailability and 1st pass metabolism have occurred (Doogue and Polasek, 2013).

Distribution poses a challenge for nanotherapeutics. Conventional metal based or uncoated NPs have very poor distribution and bioavailability as they are generally cleared from the blood circulation within $10 \mathrm{~min}$ of systemic administration regardless of their composition (Moghimi et al., 2001; Yoo et al., 2010; Suk et al., 2016). This rapid uptake and accumulation occurs primarily within the liver and is the product of 1st pass metabolism and the liver's exceptional clearance rate of xenobiotics, including nanomaterials, and the mononuclear phagocytic system (MPS). To limit this uptake into the liver, and bypass 1st pass metabolism and MPS, the most effective strategy has been PEGylation, with sub $100 \mathrm{~nm}$ PEGylated NPs having a longer circulating time than conventional NPs as reviewed by Alexis et al. (2008); Suk et al. (2016).

NP uptake by the liver and MPS is discussed in the cellular uptake section, nevertheless, it is important to discuss the role of the circulatory system in aiding these clearance pathways. Circulating proteins such as serum albumin, complement, glycoproteins, lipoproteins, coagulants and immunoglobulins bind readily to NPs (Madathiparambil Visalakshan et al., 2020). This leads to the formation of soft and hard protein coronas composed of 10-1,000 s of proteins within minutes of entering the circulatory system (Ke et al., 2017). There are vast differences in the number of proteins that can bind to NPs based on their composition, shapes and surface chemistry with differences in hard and soft protein coronas directing circulation time and differential cellular uptake (García-Álvarez et al., 2018; Richtering et al., 2020). Cloaking NPs from protein corona formation is a key strategy for targeted drug delivery (Oh et al., 2018; Alberg et al., 2020). The prefabricated attachment of serum albumin to NPs is one method utilized to avoid MPS uptake (Pitek et al., 2016). 


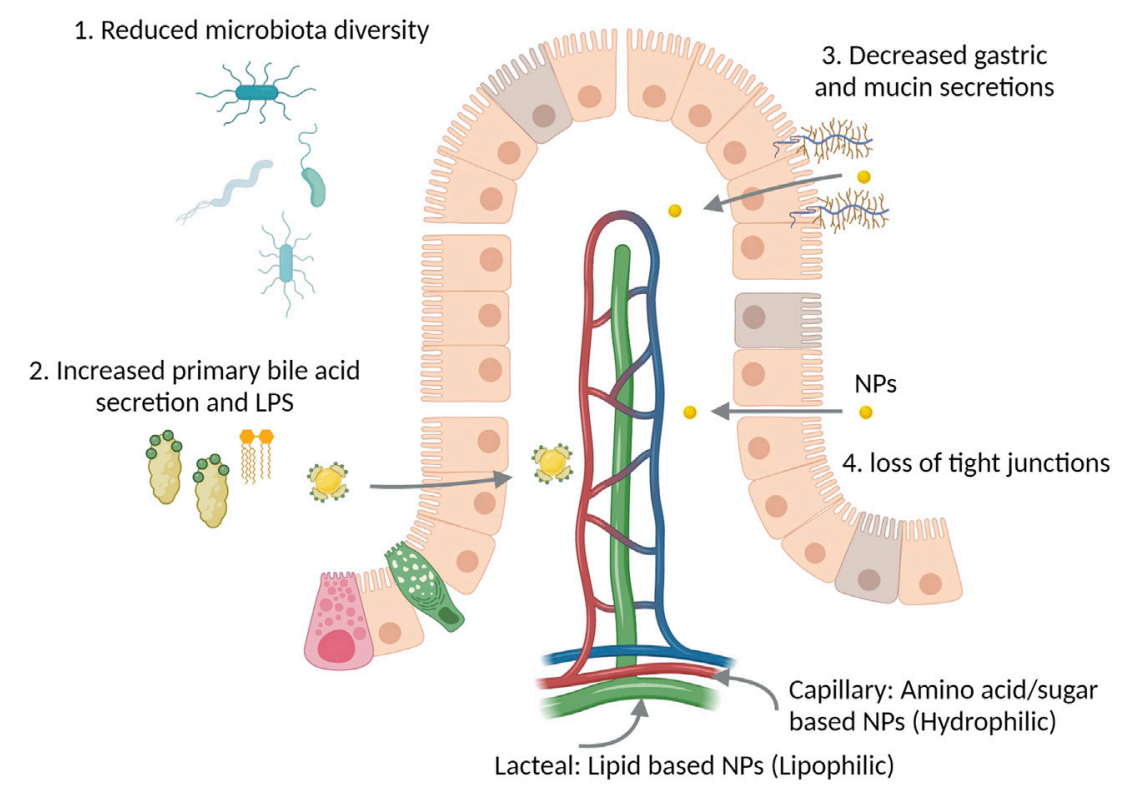

FIGURE 1 | The aging leaky gut and nanoparticle (NP) uptake. Reduction of microbiota diversity limits the metabolism of NPs, nanotherapeutics and conjugated drugs. Bile binds to the surface of NPs and facilitates their uptake via enterocytes, increased bile secretions may aid this process. Reduced gastric secretions reduce the degradation of NPs by low pH, mucins act as a physical barrier and slow the absorption of NPs, both gastric and mucin secretions are reduced with aging. Loss of tight junctions facilitates passive permeability of NPs within the leaky gut.

\section{Distribution and Aging}

Aging is associated with decreased muscle mass, body water and organ mass and increased fat mass. At very advanced ages (>85 years) there is often a decrease in fat mass associated with frailty (Hilmer et al., 2019). Each year after the age of 50, body fat increases $1 \%$ and body water decreases by $1 \%$ (Hilmer, 2008). This increases the volume of distribution of lipophilic drugs and decreases the volume of distribution of hydrophilic drugs (Mclean and Le Couteur, 2004; Klotz, 2009). This may affect the distribution of lipophilic and hydrophilic NPs in aging animals, however this has not been investigated to date. Finally, tissue perfusion decreases with age particularly to muscle and splanchnic tissues (Payne and Bearden, 2006).

NPs are composed of a broad range of materials, with ranging solubility, surface reactivity, and lipophilic, zwitterion and hydrophobic surface chemistries (Date et al., 2016). They also have broad ranging interactions with circulating materials demonstrating high and low affinity for circulating proteins (Ke et al., 2017). Collectively NPs present many characteristics of drugs, and it may be suggested that NPs may have as broad ranging level of effectiveness as drugs collectively do in aging populations.

Circulating proteins also demonstrate changes with age. a1 acid glycoprotein increases with age (Hilmer, 2008), decreasing the free fraction of basic drugs binding to albumin, particularly high affinity drugs such as levodopa, warfarin and phenytoin (Israili and Dayton, 2001). Similarly, serum albumin decreases with age (15-20\%) but rarely impacts on drug effects (Klotz, 2009) as bound drugs are inactive and drugs that have high affinity for albumin are often given at lower dosages in older patients (Reeve et al., 2015). The key risk factor in these drug formulations is increased drug availability due to reduced circulating albumin, correlating with greater side effect profiles (Reeve et al., 2015).

The protein corona may also render the transported drug inactive, because the drug can bind to non-specific sites in the proteins that make up the protein corona. Nanotherapeutics with a protein corona can release the drug or therapeutic release, but this may be limited by the scale of the protein corona (Ke et al., 2017). Ascertaining dosages of nanotherapeutics in older patients is complex because the dose of the therapeutic agent, the nanomaterial and possibly the protein corona must be considered. Aging is associated with increased inflammatory markers and complement (Singh and Newman, 2011) yet little evidence on how age-related changes in circulating proteins influence the formation of coronas on NPs, or whether this necessitates any change in dosing in older people.

The uptake and distribution of nanotherapeutics into target cells by transporters can be impeded with aging. Recently, Hunt et al. (2021) investigated the hepatic delivery of $\mathrm{Ag}_{2} \mathrm{~S}$ QD-nicotinamide mononucleotide (NMN) in young and old mice. NMN acts within the liver but has poor bioavailability in young mice and impaired efficacy in old mice (Hunt et al., 2021). NMN is transported by SLC12A8 (Grozio et al., 2019) with QD conjugation facilitating a 10fold increase in its transportation by pinocytosis and clathrinmediated endocytosis in vitro (Hunt et al., 2021). In young animals a 10,000-fold reduction in dosage was required to induce changes in glucose sensitivity in vivo. QD-NMN treatment in old 

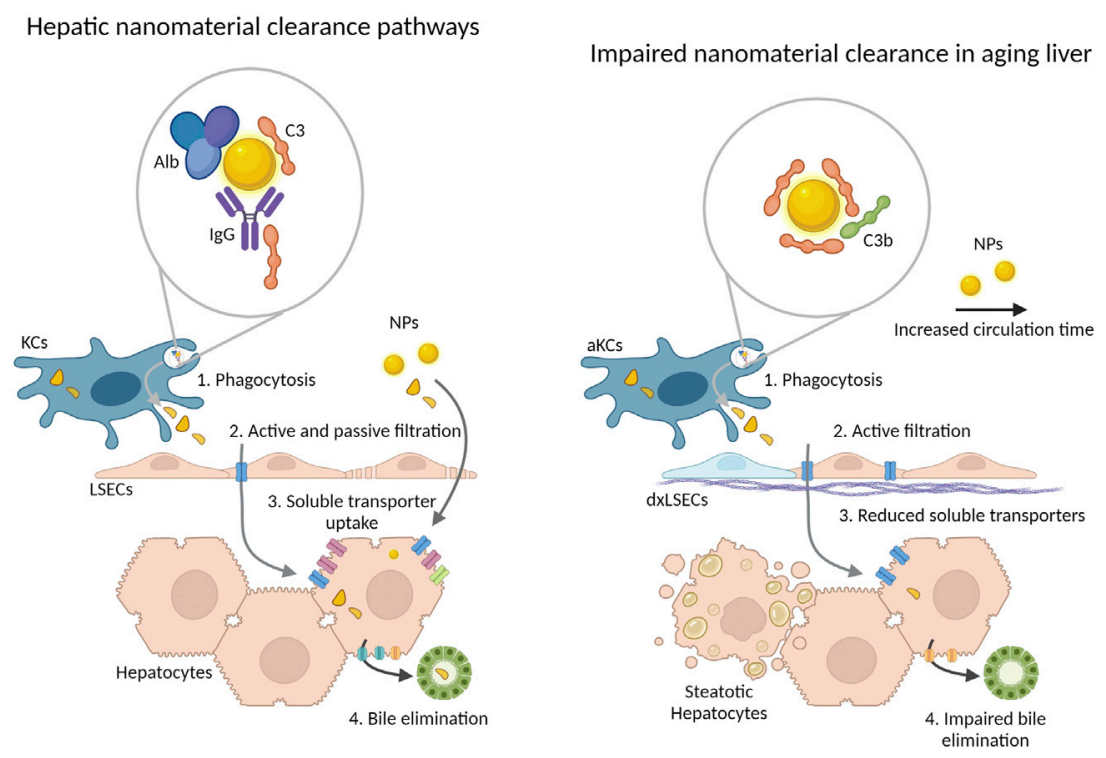

FIGURE 2 | Hepatic nanomaterial clearance pathways (left) are impaired in the aging liver (right). Aging decreases circulating albumin and lgG with increased complement activation. Increased activated immune cells promote phagocytosis of nanomaterials by modified complement pathways. Degraded nanomaterials are actively cleared across the liver endothelium with passive transport inhibited by loss of fenestrations and collagen deposits. Hepatic and bile uptake of nanomaterials are limited due to reduced soluble transporters and impaired hepatic metabolism.

animals led to improved glucose and insulin sensitivity with no effect observed with NMN treatment alone (Hunt et al., 2021). QDs increased the potency of NMN in young mice and overcame the lack of responsiveness to $\mathrm{NMN}$ in old mice.

\section{CELLULAR UPTAKE}

The MPS consists of splenic and lymph derived monocytes and macrophages along with KCs in the liver. The KCs are the first barrier that NPs must overcome in order to enter the systemic circulation with the second barrier being the scavenger endothelial cells of the liver or LSECs (Poon et al., 2019). NP uptake is primarily performed by MPS cell types and LSECs following optimization or complement attachment, however other passive and active transporters also have a role in NP clearance (Figure 2). Passive clearance of NPs from the blood is performed via nanopores in the LSECs called fenestrations (sub $120 \mathrm{~nm}$ ); these NPs enter the Space of Disse and may then be taken up by hepatocytes and directed towards to bile (Cogger et al., 2020) (discussed in Metabolism and Urinary and Biliary Elimination).

KCs are the major cells involved with the uptake of NPs by phagocytosis (Tsoi et al., 2016), yet they perform multiple other functions, some of which can influence nanotherapeutics. They have a role in tolerogenic regulation via suppression of $\mathrm{T}$ regulatory cells and stimulation of IL-10 release (Breous et al., 2009). KCs also facilitate cross talk between dendritic cells (DCs), natural killer cells and natural killer $\mathrm{T}$ cells (Nguyen-Lefebvre and Horuzsko, 2015). KCs are strongly activated by C3 complement products which activates phagocytosis and increases uptake of NPs (Helmy et al., 2006; NguyenLefebvre and Horuzsko, 2015). On the other hand CD47mediated immune suppression leads to a reduction of NP uptake by macrophages including KCs (Yong et al., 2017).

$\mathrm{C} 3 \mathrm{a}$ and $\mathrm{C} 3 \mathrm{~b}$ are common components of protein coronas that encapsulate NPs. In a recent study the attachment of $\mathrm{C} 3 \mathrm{a}$ and $\mathrm{C} 3 \mathrm{~b}$ to NPs was shown to be dependent on primary immunoglobulin binding to NPs, particularly IgG (Vu et al., 2019). IgG provided a scaffolding for $\mathrm{C} 3 \mathrm{~b}$ binding, with the epitope for NP attachment still to be identified (Vu et al., 2019). This is not surprising as IgG can naturally absorb non-specifically onto multiple pathogens, antigens, surfaces, proteins and is used as a control in flow cytometry for this property. IgG can attach to SPIONs, liposomes, Fe NPs and Au NPs (Bell et al., 2013; Vu et al., 2019). Macrophages also recognize NPs by the attachment of Fc or fibronectin (Neuberger et al., 2005). In addition, opsoninindependent scavenger receptors on macrophages also facilitate NP clearance (Walkey et al., 2012). Similarly, this is also performed by LSECs (Monopoli et al., 2012; Tenzer et al., 2013). The LSEC receptors involved in NP uptake remain to be identified, it is likely that several receptors facilitate uptake with varying effectiveness, of particular interest is stabilin- 2 given that liposome based NPs are endocytosed by stabilin-2 in zebra fish (Campbell et al., 2018).

The role of the scavenger endothelium, and how scavenging fits in relative to phagocytosis needs to be discussed in the context of NP clearance. Phagocytosis is performed by KCs, DCs and mononuclear cells while clathrin-mediated scavenging is a form of pinocytosis (cellular drinking) and transcytosis/endocytosis which facilitates uptake of soluble sub-200 nm materials 
(Sørensen et al., 2012). This difference is critical as NPs retained within phagocytic cells (particularly non-degradable NPs) have long term retention (months to years) while NPs scavenged by clathrin-mediated-endocytosis are degraded, exocytosed and cleared within the urine or bile within days to weeks (Zhang et al., 2016; Hunt et al., 2021). This provides a rationale for designing nanomedicines that are preferentially targeted by scavenging rather than phagocytosis.

Endothelial transcytosis and endocytosis are mediated by clathrin coated pits. Visualization of this process was performed by Kishimoto and Tavassoli (1987) using an Fetransferrin complex labelled with nano-sized colloidal gold. This complex was internalized and transported via tubules and vesicles followed by exocytosis into the space of Disse, the space between the LSECs and hepatocytes. Transcytosis and endocytosis are either receptor mediated or independent. Independent transcytosis occurs for plasma solutes and macromolecules (limited to $70 \mathrm{~nm}$ by the size of clathrincoated pits) such as glycogen, dextran and ferritin (Simionescu et al., 2009). Clathrin-mediated transcytosis facilities the transport LDL, transferrin, ceraloplasmin, insulin and albumin (alb) (Simionescu et al., 2009). Recently included in this list are chemokines CXCL10 and MCP-1, and glycated proteins (Li et al., 2013; Neumann et al., 2015; Shetty et al., 2018). The clathrincoated pits contain receptors of IL-1, p75 (death receptors), insulin, AGE, CP, Tf, Alb, EGF, HDL and LDL receptors for receptor mediated transcytosis (Simionescu et al., 2009).

Endocytosis by LSECs involves the degradation and metabolism of blood borne waste proteins and xenobiotics via lysosomal formation; this property is also referred to as scavenging. There are five scavenging receptor classes expressed on LSECs (A, B, E, H and L) that mediate this process. In two recent reviews, Pandey et al. (2020) and Bhandari et al. (2021) highlighted the scope of molecules that are scavenged by these receptors. These receptors mediate the LSECs uptake and degeneration of blood borne waste molecules and colloids under $200 \mathrm{~nm}$. Previously we investigated whether it was possible to target specific clearance pathways in vitro and in vivo using biopolymer coatings to facilitates endocytosis or avoidance of liver phagocytic cells and scavenger endothelial cells with hepatocyte-only uptake (Hunt et al., 2020). Coating with formaldehyde-treated serum albumin (FSA) was increased scavenger endothelial cell uptake in vitro and in vivo via stabilins 1 and 2. In the in vivo context, heparin coating facilitated uptake by hepatocytes but not KCs or LSECs (Hunt et al., 2020).

\section{Cellular Uptake and Aging}

Hepatic cellular uptake of many drugs and NPs is dependent on the rate of supply to the liver. This is influenced by hepatic blood flow, the rate of transfer from blood to hepatocytes (involving both passive and active transcytosis across the endothelium), and the metabolic rate or 'intrinsic clearance' of hepatocytes (i.e., flow capacity, dissolution capacity and metabolism capacity respectively) (Mclean and Le Couteur, 2004).

Aging is associated with a $20-50 \%$ reduction in hepatic blood flow which will reduce the hepatic clearance and first pass metabolism of flow-dependent substrates (Mclean and Le
Couteur, 2004). The passive transfer from the blood to hepatocytes is affected by defenestration of LSECs, endothelial thickening and collagen deposition, collectively referred to as pseudocapillarization (Le Couteur et al., 2008). These aging changes also reduce the hepatic clearance of flow-limited substrates. This may be an advantage for orally administered NPs given in old age, because lower doses will generate similar concentrations as obtained at younger ages. For example, we observed that old mice had double the systemic concentration of orally administrated $\mathrm{Ag}_{2} \mathrm{~S}$ QDs than young mice despite the same dose (Hunt et al., 2020; Hunt et al., 2021). The hepatic clearance of substrates that undergo capacity-limited clearance will also be reduced in old age as a result of reductions in liver mass and enzyme activity (Le Couteur et al., 2002; Le Couteur et al., 2008).

Active transporters are affected by aging within the liver. Decreased activity of P-gp has been shown in the liver, but not the endothelium or intestines (Warrington et al., 2004). The expression of LSEC SRH-2 (stabilin-2), the main scavenger receptor on LSECs, remains largely unchanged with age, but LSECs have a slightly reduced ability to endocytose ligands via this receptor in LSECs from old rats (SimonSantamaria et al., 2010). The SLC transporters OCTs, OCTNs, NPTs, OATPs and APTs are decreased with age (Fu et al., 2012; Cogger et al., 2013; Hou et al., 2014; Wu and Lin, 2019). Broad inhibition of these soluble transporters inhibits PLGA NPs, QD uptake into hepatocytes (Press et al., 2014; Zhang et al., 2018; Hunt et al., 2021). Overall, aging may impair NP uptake and clearance by the MPS and liver resulting in greater bioavailability in older patients.

\section{METABOLISM}

Drug metabolism usually results in an active drug becoming inactive and water soluble, therefore able to be excreted in urine or bile. Drug metabolism occurs via two pathways: phase I pathways (oxidation and reduction, hydrolysis) and phase II pathways (conjugation with water soluble substrates such as glutathione, sulfate, acetate and glucuronide) (Klotz, 2009). While the majority of metabolism occurs in the liver, CYP3A4 is also present in the intestine, kidneys, lung, brain, placenta and lymphocytes (Anzenbacher and Anzenbacherova, 2001). The majority of hepatic metabolism is via P450 enzymes CYP3A4 (52\%), CYP2D6 (30\%) and CYP2C9/10/19 (11\%) (Anzenbacher and Anzenbacherova, 2001).

Nanotherapeutics and NPs present a different challenge in terms of their metabolism as their have rapid cellular uptake via the MPS (phagocytic cells) and LSECs, followed by phagolysosome/lysosome mediated degradation. Enzymatic metabolism also occurs during this process and NPs are oxidized and reduced to improve their solubility for renal and biliary clearance.

Degradation of nanomaterials by phagocytic cells (MPS) is promoted following opsonization facilitated by $\mathrm{C} 3 \mathrm{~b}$ or/and IgG. Phagocytosis is promoted these opsonins proteins via either complement receptor or $\mathrm{Fc} \gamma \mathrm{R}$ signaling in $\mathrm{KCs}$, neutrophils and macrophages. The formation of the phagosome differs 
between the two signaling cascade. Complement receptor signaling facilitating activation of Rho GTPase, ROCK, Arp 2/ 3 complexes and mDia (Uribe-Querol and Rosales, 2020), while $\mathrm{F} c \gamma \mathrm{R}$ signaling activates the Src family kinases leading to the activation of PI3K, PKC, Rac and ERK (Uribe-Querol and Rosales, 2020). The phagosome facilitate internalization via modification to the actin cytoskeleton. Once internalized the phagosome transitions to a phagolysosome via the accumulation of V-ATPase, NADPH oxidase complexes, myeloperoxidation and hydrolytic enzymes, lysozymes and lipases (Uribe-Querol and Rosales, 2020). V-ATPase promotes an acidic environment ( $\mathrm{pH} \mathrm{4.5)} \mathrm{(Marshansky} \mathrm{and} \mathrm{Futai,} \mathrm{2008),}$ oxidase complexes produce reactive oxygen species (ROS) and superoxide $\left(\mathrm{O}_{2}{ }^{-}\right)$(Babior, 2004; Minakami and Sumimoto, 2006). $\mathrm{O}_{2}^{-}$dismutates to hydrogen peroxide, which based on coenzymes (myeloperoxidase) can produce other radical ions $\left(\mathrm{Cl}^{-}\right)$(Nauseef, 2014). In addition to the phagolysosome, phagocytic cells also engender an inflammatory environment via ROS generation, secretion of inflammatory meditators, degranulation of antimicrobial molecules and production of cytokines (Uribe-Querol and Rosales, 2020).

The degradation via phagolysosomes of different NP materials has been reported. Degradation of carbon nanotubes is mediated via hypochlorite and peroxynitrite (myeloperoxidase-induced) pathways (Ding et al., 2017). $\mathrm{MnO}_{2} \mathrm{NPs}$ are completely decomposed to form free $\mathrm{Mn}^{2+}$ ions that are readily excreted via the kidneys (Liu et al., 2017). Calcium based NPs are stable under neutral pH but disintegrate at pH 5.0 (Ueno et al., 2005). Polystyrene and $\mathrm{TiO}_{2}$ NPs activate the production myeloperoxidases for ROS mediated degradation (Sanfins et al., 2018).

Comparatively, Au NPs present a challenge for degradation as chemically $\mathrm{Au}$ is inert; yet it has been shown to promote a localised inflammatory response (Oh and Park, 2014). This inflammatory response is mediated by the phagocytic cell attempting to degrade Au NPs. Exocytosis of non-degraded $\mathrm{Au}$ NPs from macrophages is mediated by the presence of surface coatings (e.g., PEGylation) or, as is the case with conventional $\mathrm{Au}$ NPs, they have a long retention within the phagocytic cell (Oh and Park, 2014). To examine the long term retention, Kolosnjaj-Tabi et al. (2015) examined the 1 year fate of $\mathrm{Au}$ and $\mathrm{Fe}$ coated $\mathrm{Au}$ NPs in vivo. Conventional $\mathrm{Au}$ NPs demonstrated a $30 \%$ retention 1 day after injection that reduced to $12 \%$ after 1 year within the liver; comparatively $\mathrm{Fe}$ coatings demonstrated $80 \%$ retainment for up to 1 week and $7 \%$ retainment over 1 year. Fe NPs are degraded by phagocytic cells and are used clinically in the form of ferric carboxymaltose, $\mathrm{Fe}$ sucrose and $\mathrm{Fe}$ dextran as therapeutics for Iron deficiency (Lyseng-Williamson and Keating, 2009). Differences in their cellular uptake into phagocytic cells have been observed with Fe sucrose demonstrating complement mediated uptake (Faria et al., 2019). These studies highlight the importance of degradability of the metal NPs.

Metal NPs also present toxicity challenges highlighted by a recent review (Egorova and Ananikov, 2017). It was concluded that the toxicity of a metal NP depends on multiple factors (oxidation state, ligand, solubility and morphology) that contribute to potential toxic effects on both humans and the environment (Egorova and Ananikov, 2017). During the course of absorption-distribution-metabolism-excretion (ADME), metal NPs will have multiple modifications and should be considered holistically. Heavy metal poisoning in humans is due to aluminium, arsenic, beryllium, cadmium, copper, chromium, iron, lead, lithium, manganese, mercury, nickel, silver, thallium, tin and zinc (Ibrahim et al., 2006). To address the risk of heavy metal poisoning there are standardised guidelines about the concentration of each metal that can be present in water, air and food products. These guidelines should be considered when developing metal based nanotherapeutics, with alternative materials to be used even for very low clinical risk metals.

LSECs have a critical role in degradation of nanomaterials (Poon et al., 2019) due to their immense endocytic capacity (Sørensen et al., 2012). Using a variety of receptors [mannose receptor, stabilins 1/2 (a.k.a. SRH1/2), and endocytic Fc $2 \mathrm{~B}$ receptor] LSECs recognize and internalize pathogen associated molecular patterns, cellular debris and immune complexes [including small circulating IgG complexes (Malovic et al., 2007)]. For example, LSEC clear gram amounts of denatured collagen and procollagen I N-terminal peptides arising from bone turnover via the mannose receptor (Mousavi et al., 2007) and stabilin-2/SRH-2 (Mccourt et al., 1999), respectively. LSECs also clear BK polyoma virus (Simon-Santamaria et al., 2014), bacteriophages (Øie et al., 2020) and adenoviruses (Ganesan et al., 2011). The degradation capacity of LSECs is dependent on the circulating lysosomal enzymes that are taken up by LSECs via mannose receptor mediated endocytosis for the hydrolysis of endocytosed proteins, lipids and nucleic acids (Elvevold et al., 2008). We have shown selective targeting of LSECs for degradation of $\mathrm{Ag}_{2} \mathrm{~S}$ QDs conjugated to a scavenger receptor binding ligand in vivo (Hunt et al., 2020). Attachment of this ligand lead to a 5-fold increase in the endocytic uptake rate compared to unconjugated $\mathrm{Ag}_{2} \mathrm{~S}$ QDs, with no differences in whole animal excretion rate or volume observed.

An important point is that phagocytic cells and LSECs degrade or solubilize NPs with the aim of creating a soluble and excretable product that may be cleared by the kidneys or transported by soluble carriers (SLCs and SLCOs) to the bile. Problematically, even if the base nanomaterial is degraded it may still be reactive and able to promote cellular stress and damage. This action is most clearly identified with metal NPs and highlighted by the spectrum of metals that induce toxicity. For example, CeSe/ZnS cause high levels of oxidative stress, cellular damage and DNA damage compared to Ag and carbon-based NPs (Malaviya et al., 2019).

\section{Metabolism and Aging}

Aging affects phagocytic cells of the MPS, LSECs, IgG and complement pathways. KCs and macrophages have increased cell numbers, reduced phagocytosis capacity but increased production of cytokines, particularly IL-6 (Hunt et al., 2019). Within the liver this local inflammatory environment is coupled with senescence-associated secretions from hepatocytes to drive increased recruitment and activation 
of immune cells (Hunt et al., 2019). LSECs undergo pseudocapillarization loss of fenestrations, deposition of a basement membrane and increased cell adhesion markers (facilitates increased KC attachment) (Hunt et al., 2019) which inhibits passive clearance leading to in increased drug concentrations in systemic circulation (Mitchell et al., 2011).

Circulating IgG is substantially reduced with aging (Buckley and Dorsey, 1970) due to glycosylation of IgG impairing its function (Gudelj et al., 2018). This may reduce opsonization of NPs in aging animals but has not been investigated to date.

Complement pathways also demonstrated broad changes with aging. The complement cascades via the classical, mannan and alternative pathways both adapt and change with age (Gaya Da Costa et al., 2018). NPs, particularly $>30 \mathrm{~nm}$ anionic liposomes, have been observed to act via all three pathways via different proteins within the protein corona. In the classical pathway IgG acting as the initiator; in the mannan pathway lectin proteins conjugate to mannose; and in the indirect pathway via direct $\mathrm{C} 3 \mathrm{~b}$ attachment to NPs (La-Beck et al., 2021). With age, classical and alternative pathways have increased activity (Gaya Da Costa et al., 2018). The mannan pathway has been shown to have decreased activity (Gaya Da Costa et al., 2018).

Overall, there are multiple factors that may affect the metabolism of nanotherapeutics in aging models and older patients. The reduction in phagocytosis by phagocytic cells and passive and active clearance by LSECs suggest prolonged circulation of nanotherapeutics may occur with aging. This conclusion is supported by our study showing a doubling of circulating concentrations of QD conjugated metformin in old mice compared to younger mice (Hunt et al., 2020; Hunt et al., 2021). Reduced circulating IgG and serum albumin will further aid this delay in optimization or conjugation of NPs in vivo. Given the broad changes in the complement cascade with aging, future studies need to investigate aged and animal models with multi-morbidities to determine the efficacy of nanotherapeutics prior to clinical use particularly from an immunological focus.

\section{URINARY AND BILIARY ELIMINATION}

Urinary clearance can occur via passive or active processes. Passive clearance occurs via glomerular filtration and is dependent on the drug/nanotherapeutic solubility, size (hydrodynamic diameter $<6 \mathrm{~nm}$ ) and protein binding status (albumin or corona coated materials are not readily excreted). Passive clearance is dependent on glomerular filtration rate (GFR) or the flow of plasma from the glomerulus into the Bowman's space.

Therapeutics may also enter the renal tubules by active secretion across the renal proximal tubule cells facilitated by SLC and adenosine triphosphate (ATP)-binding cassette (ABC) transporters (Yin and Wang, 2016). These transporters include OCT2, OCT 1/3, OAT2, OATP4C (SLCO4C), MATE1/2, OCTN1/2, P-gp, MRP2/4, OAT4, OAT10 and URAT1 (Yin and Wang, 2016). There is substantial overlap between active urinary secretion transporters and biliary excretion transporters.
Hepatic biliary transport is mediated by MDR1, MDRP, P-gp, ABCB11, ABCG2, aquaporin 8/9, BCRP and MATE1 to facilitate waste transportation into the bile cannula (Jetter and KullakUblick, 2020). Hepatic bile is composed of water, bile salts, cholic acid and chenodexycholic acid produced from CYP450 mediated metabolism of cholesterol bilirubin and fats.

Collectively these channels contribute to the active excretion of drugs, xenobiotics and nanomaterials; the overlap between the two sites is due to the enzymatic breakdown occurring in a broad range of areas (intestine, kidneys, lung, brain, placenta and lymphocytes) with soluble blood born waste materials continuously being excreted (Anzenbacher and Anzenbacherova, 2001).

Urinary and biliary excretion of NPs has been shown to occur in a size dependent manner with Au NPs (Poon et al., 2019). Au NPs under $6 \mathrm{~nm}$ are more readily cleared via urinary excretion (Poon et al., 2019). NPs larger than this demonstrates a size dependent relationship with active excretion via biliary clearance with smaller NPs (down to 7-8 nm) having greater biliary clearance, because they have less $\mathrm{KC}$ uptake as well as undergo passive filtration through the fenestrated surface of the liver endothelium (Tsoi et al., 2016; Poon et al., 2019).

Several types of NPs have very high biliary clearance. Seo et al. (2015) showed that injected $38 \mathrm{~nm}$ oleic acid micelles capped with polysorbate 60 had $85 \%$ biliary clearance within $72 \mathrm{~h}$. Souris et al. (2010) demonstrated high biliary clearance with mesoporous silica NPs conjugated with indocyanine. Lastly, we have demonstrated high biliary clearance with orally administrated

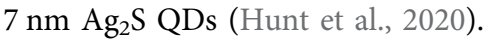

Active elimination via different transporters has been shown for nanotherapeutics and more broadly, for xenobiotics. P-gp also known as multi drug resistant protein 1 (MDR1) or ABCB1, is the most common xenobiotic transporter and is expressed in most tissues (Jetter and Kullak-Ublick, 2020). P-gp is also highly expressed in some cancer cells and there have been several strategies to overcome $\mathrm{P}$-gp facilitated removal of nanotherapeutics from targeted cancers (Niazi et al., 2016). A potential side effect of these strategies may be reduced long-term clearance and broader distribution of these NPs. P-gp is expressed 7-fold higher in the GI tract and blood brain barrier compared to hepatocytes (Cascorbi, 2011). Impaired P-gp clearance may contribute to long term retention and toxicity of NPs.

Other transporters with demonstrable roles in biliary excretion include OAT2 (SLC22A7) MATE1 And Aq9. OAT2 mediates the uptake of xenobiotics (Jetter and Kullak-Ublick, 2020), while MATE1 (SLC47A1) acts as a scavenger for P-gp to facilitating its excretion into the bile (Jetter and Kullak-Ublick, 2020). Finally, Aq9 permits the diffusion of mannitol and critically PEG below $900 \mathrm{Da}$ for urinary and biliary excretion (Javitt, 2014).

These active uptake pathways, particularly the SLC channels, are present throughout the body and most heavily in the GI tract and liver. This almost ubiquitous presence highlights a critical issue with targeting and utilizing these channels to improve bioavailability as there is likely increased clearance with greater precision targeting of these transporters. Still, this challenge presents an opportunity as drug delivery may be 
facilitated during this rapid clearance if the therapeutic agent can be released during a short time frame.

\section{Clearance and Aging}

With age GFR (passive filtration of ultra-particles from the plasma) is reduced by $15-40 \%$ (Mclean and Le Couteur, 2004). Renal plasma flow also decreases with age at a faster rate than GFR as a result of increased renal vascular resistance (Fliser et al., 2005). Age-related changes in renal function are a very important consideration when calculating the drug dosage given to older people (such as aminoglycosides, digoxin, and dabigatran). This is further confounded by prevalent coexistent comorbidities (diabetes, hypertension and heart failure) or nephrotoxic drugs (nonsteroid anti-inflammatory).

Active transporters (as highlighted in the cellular uptake section and above) decrease with age. Differences between renal and hepatic changes with age are evident for P-gp which showed decreased expression in kidneys and reduced activity in the liver (Warrington et al., 2004). Within the kidney, decreased expression in old age was observed for OCT2, OATP4C1, Mdr1b and MATE1; while OAT1 and 3, OCT1, BCRP, MRP2 and 4 and MATE2 show no changes with age (Xu et al., 2017). Within the liver, of the 101 xenobiotic-processing genes, $40-43 \%$ of transporters are downregulated with age (Fu et al., 2012). This was contributed to reduced phase 1 metabolism Increased expression was only observed for OAT2 and GSTM2 within the liver (Fu et al., 2012). These studies highlight that organic cation transporters consistently demonstrated downregulation in multiple organs. As highlighted in the absorption section metformin is a primary drug candidate to demonstrate the benefits of nano-drug efficacy in aging. We demonstrated that there are improved pharmacokinetics and pharmacodynamics when metformin is conjugated to QDs aging animals (Hunt et al., 2020; Hunt et al., 2021). We suggest that other OCT1/2 transporter drugs (e.g., anti-viral medications: zidovudine, acyclovir and ganciclovir) are ideal candidates for nanoformulation to improve the efficacy of drug treatment in older patients. Previously we have also reviewed other potential drug therapeutics for hepatic specific targeting with nanotechnology (Hunt et al., 2018).

\section{NANOTHERAPEUTICS AND AGING}

Even though older people are the major users of therapeutic agents, there are very few studies examining the effects of aging on the pharmacology of nanomedicines. One study reported the effects of aging on the biodistribution of citrate coated Fe NPs $(10 \mathrm{~nm})$. Old mice had greater Fe NP retention in the liver and kidney while young mice predominantly retained Fe NPs within the spleen. Comparing old and young mice, greater iron NP uptake was observed in the lung, brain, spleen and liver of older mice, however no differences in clinical or histological outcomes were observed between the age groups (Pinheiro et al., 2019). Another study examined silica NPs to limit age-related bone loss (Weitzmann et al., 2015). We studied the effects of aging on orally administrated metformin or $\mathrm{NMN}$ coated $\mathrm{Ag}_{2} \mathrm{~S}$ QDs (Hunt et al., 2020; Hunt et al., 2021). Overall, these few studies have not detected any major age-related toxicity concerns. However, NP toxicity studies in 18 month old mice found a loss of stress responses in older animals (Zhang et al., 2012; Pomatto et al., 2018). Investigation into the effects of aging on the pharmacology of NPs and subsequent efficacy and safety in clinical trials will be critical for any nanotherapeutics that will be used in older patients.

\section{REGULATORY CONSIDERATIONS}

Nanomaterials, similarly to linkers, antibodies, peptides and viral vectors, change the efficacy and toxicity of drugs. This is important because nanomaterial may address the efficacy and toxicity weaknesses of novel drug formulations that have failed in phase 2/3 clinical trials (Harrison, 2016). The limited translation of nanomedicines further highlights the difficulty in achieving this task (He et al., 2019). Regulatory issues with nanotechnology are currently addressed by classifying nanotherapeutics or nanodrugs as drugs themselves, regardless of whether the nanotechnology is proposed to be inactive or active in their actions within the body. FDA guidelines suggest, like for all drug formulations, that early phase in vivo studies require haematology, clinical chemistry, gross pathology, immune response, tissue weights and histological examination. These existing guidelines may create difficulties with a nano-drugs designed to have prolonged circulation and be resistant to metabolism and clearance. Potential accumulation in off target tissues and reduced biodegradability may be significant barriers to regulatory approval. Additionally, the use of nanomaterials that have a highly reactive surface chemistry may contribute to ROS generation, particularly with heavy metals (Malaviya et al., 2019). This presents great difficulty in regulatory assessments as nanomaterials, despite their advantages based on their size and reactivity, are effectively drugs themselves with a broad range of side effects. It is therefore of critical importance that nano absorption, distribution, cellular uptake, metabolism, drug action and removal be understood and potentially provided with separate regulatory processes specifically designed with the properties of nanomaterials in mind.

With the above considerations nanotechnology should be considered an enabling technology platform that can have broad applications from biotechnology, bio-medicine, information technology and cognitive technology. Previously, regulatory regimes worldwide were decentralized, fragmented and presented gaps and challenges (Devasahayam, 2019; Allan et al., 2021). On the other hand, as reviewed by Devasahayam (2019) the current legal metronomy within the global setting is adequate to respond to the measurements required for nanotechnology (nanometrometry). In a recent review Halamoda-Kenzaoui et al. (2021) described the regulatory framework and technical approaches required for safety and quality control of nanotherapeutics. Both the European Medicine Agency (EMA) and FDA have released several guidance documents that outline the parameters to consider, 
including ICH guidelines for medical products and CEN/ISO standards (Halamoda-Kenzaoui et al., 2021). Due to the complex nature and propensity to interact with biological systems additional assessments are required. Of critical interest have been the key discussion points of this review, phagocytosis, inflammation and complement activation. Relating to ADME challenges for in silico and humanized biodistribution remain key areas to address. As highlighted by this review within older patients there will be additional changes in ADME that cannot be predicted by young animal models. Finally, additional studies must also be performed in aging animal models to aid existing PBPK models.

\section{CONCLUSION}

The aim of this review was to provide an overview of the broad changes in drug absorption, distribution, cellular uptake, metabolism, drug action and removal facilitated by nanomaterials and how these systems are affected by aging. We have identified the areas of overlap and advantages for nanotherapeutics in aging (Table 1). Nanotherapeutics provide the opportunity to greatly enhance absorption of therapeutics in older people with impaired uptake of specific soluble transporter drugs, delayed uptake time and reduced absorption of weakly basic drugs. These benefits are afforded because nanotherapeutics are broadly absorbed by multiple soluble transporters and utilize macropinocytosis and clathrin endocytosis to increase drug bioavailability. Additionally, nanotherapeutics demonstrate conventional and highly specific distribution and clearance by

\section{REFERENCES}

Alam, F., Al-Hilal, T. A., Chung, S. W., Seo, D., Mahmud, F., Kim, H. S., et al. (2014). Oral Delivery of a Potent Anti-angiogenic Heparin Conjugate by Chemical Conjugation and Physical Complexation Using Deoxycholic Acid. Biomaterials 35, 6543-6552. doi:10.1016/j.biomaterials.2014.04.050

Alberg, I., Kramer, S., Schinnerer, M., Hu, Q., Seidl, C., Leps, C., et al. (2020). Polymeric Nanoparticles with Neglectable Protein Corona. Small 16, 1907574. doi:10.1002/smll.201907574

Alexis, F., Pridgen, E., Molnar, L. K., and Farokhzad, O. C. (2008). Factors Affecting the Clearance and Biodistribution of Polymeric Nanoparticles. Mol. Pharmaceutics 5, 505-515. doi:10.1021/mp800051m

Allan, J., Belz, S., Hoeveler, A., Hugas, M., Okuda, H., Patri, A., et al. (2021). Regulatory Landscape of Nanotechnology and Nanoplastics from a Global Perspective. Regul. Toxicol. Pharmacol. 122, 104885. doi:10.1016/j.yrtph.2021.104885

An, R., Wilms, E., Masclee, A. A. M., Smidt, H., Zoetendal, E. G., and Jonkers, D. (2018). Age-dependent Changes in GI Physiology and Microbiota: Time to Reconsider. Gut 67, 2213-2222. doi:10.1136/gutjnl-2017-315542

Anselmo, A. C., and Mitragotri, S. (2019). Nanoparticles in the Clinic: An Update. Bioeng. Transl Med. 4, e10143. doi:10.1002/btm2.10143

Anselmo, A. C., and Mitragotri, S. (2016). Nanoparticles in the Clinic. Bioeng. Translational Med. 1, 10-29. doi:10.1002/btm2.10003

Anzenbacher, P., and Anzenbacherová, E. (2001). Cytochromes P450 and Metabolism of Xenobiotics. Cmls, Cel. Mol. Life Sci. 58, 737-747. doi: $10.1007 / \mathrm{pl} 00000897$

Babior, B. M. (2004). NADPH Oxidase. Curr. Opin. Immunol. 16, 42-47. doi:10.1016/j.coi.2003.12.001

Behrens, I., Pena, A. I. V., Alonso, M. J., and Kissel, T. (2002). Comparative Uptake Studies of Bioadhesive and Non-bioadhesive Nanoparticles in Human the liver, potentially bypassing recognized age-related impairments in first pass metabolism, reductions in serum albumin, blood flow and passive clearance pathways. Challenges for nanotherapeutics in older patients will be based on the local inflammatory profiles within the liver and in circulation. Broad differences in complement, IgG and protein binding may drastically shift the efficacy and long-term toxicity of nanotherapeutics in older patients and highlights the need to investigate aging animal models and relevant metabolic pathways in older people to better understand how nanotechnology will translate into patients and the clinic.

\section{AUTHOR CONTRIBUTIONS}

$\mathrm{NH}$ composed the original draft; VC, DL, PM, and ZK revised and edited the draft. All authors have reviewed and approved submission.

\section{FUNDING}

NHMRC project grants: no. 1141234; Sydney Medical School Foundation McKnight Bequest, The University of Sydney DVCR Research Equity Fellowship, The University of Sydney Seed Grant, Research Council of Norway grants: 325446; 328617 and 328965; European Union grants: H2020-MSCA-ITN2017 no. 777181 and HORIZONEIC-2021PATHFINDEROPEN-01 no. 101046928; and the University of Tromsø (UiT), Faculty of Health Sciences travel grant to PM.

Intestinal Cell Lines and Rats: The Effect of Mucus on Particle Adsorption and Transport. Pharm. Res. 19, 1185-1193. doi:10.1023/a:1019854327540

Bell, N. C., Minelli, C., and Shard, A. G. (2013). Quantitation of IgG Protein Adsorption to Gold Nanoparticles Using Particle Size Measurement. Anal. Methods 5, 4591-4601. doi:10.1039/c3ay40771c

Bhandari, S., Larsen, A. K., Mccourt, P., Smedsrød, B., and Sørensen, K. K. (2021). The Scavenger Function of Liver Sinusoidal Endothelial Cells in Health and Disease. Front. Physiol. 12, 757469. doi:10.3389/ fphys.2021.757469

Bi, Y., Marcus, A. K., Robert, H., Krajmalnik-Brown, R., Rittmann, B. E., Westerhoff, P., et al. (2020). The Complex Puzzle of Dietary Silver Nanoparticles, Mucus and Microbiota in the Gut. J. Toxicol. Environ. Health B 23, 69-89. doi:10.1080/10937404.2019.1710914

Bischoff, S. C. (2016). Microbiota and Aging. Curr. Opin. Clin. Nutr. Metab. Care 19, 26-30. doi:10.1097/mco.0000000000000242

Borges, O., Cordeiro-Da-Silva, A., Romeijn, S. G., Amidi, M., De Sousa, A., Borchard, G., et al. (2006). Uptake Studies in Rat Peyer's Patches, Cytotoxicity and Release Studies of Alginate Coated Chitosan Nanoparticles for Mucosal Vaccination. J. Controlled Release 114, 348-358. doi:10.1016/ j.jconrel.2006.06.011

Breous, E., Somanathan, S., Vandenberghe, L. H., and Wilson, J. M. (2009). Hepatic Regulatory T Cells and Kupffer Cells Are Crucial Mediators of Systemic T Cell Tolerance to Antigens Targeting Murine Liver. Hepatology 50, 612-621. doi:10.1002/hep. 23043

Buckley, C. E., and Dorsey, F. C. (1970). The Effect of Aging on Human Serum Immunoglobulin Concentrations. J. Immunol. 105, 964-972.

Campbell, F., Bos, F. L., Sieber, S., Arias-Alpizar, G., Koch, B. E., Huwyler, J., et al. (2018). Directing Nanoparticle Biodistribution through Evasion and Exploitation of Stab2-dependent Nanoparticle Uptake. ACS Nano 12, 2138-2150. doi:10.1021/acsnano.7b06995 
Cascorbi, I. (2011). P-glycoprotein: Tissue Distribution, Substrates, and Functional Consequences of Genetic Variations. Handb Exp. Pharmacol. 2011, 261-283. doi:10.1007/978-3-642-14541-4_6

Chai, G.-H., Xu, Y., Chen, S.-Q., Cheng, B., Hu, F.-Q., You, J., et al. (2016). Transport Mechanisms of Solid Lipid Nanoparticles across Caco-2 Cell Monolayers and Their Related Cytotoxicology. ACS Appl. Mater. Inter. 8, 5929-5940. doi:10.1021/acsami.6b00821

Claesson, M. J., Cusack, S., O’sullivan, O., Greene-Diniz, R., De Weerd, H., Flannery, E., et al. (2011). Composition, Variability, and Temporal Stability of the Intestinal Microbiota of the Elderly. Proc. Natl. Acad. Sci. 108, 4586-4591. doi:10.1073/pnas.1000097107

Cogger, V. C., Hunt, N. J., and Le Couteur, D. G. (2020). Fenestrations in the Liver Sinusoidal Endothelial Cell. The Liver, 435-443. doi:10.1002/ 9781119436812.ch35

Cogger, V. C., Svistounov, D., Warren, A., Zykova, S., Melvin, R. G., Solon-Biet, S. M., et al. (2013). Liver Aging and Pseudocapillarization in a Werner Syndrome Mouse Model. J. Gerontol. A. Biol. Sci. Med. Sci. 69, 1076-1086. doi:10.1093/ gerona/glt169

Coyuco, J. C., Liu, Y., Tan, B. J., and Chiu, G. N. (2011). Functionalized Carbon Nanomaterials: Exploring the Interactions with Caco-2 Cells for Potential Oral Drug Delivery. Int. J. Nanomedicine 6, 2253-2263. doi:10.2147/IJN.S23962

Date, A. A., Hanes, J., and Ensign, L. M. (2016). Nanoparticles for Oral Delivery: Design, Evaluation and State-Of-The-Art. J. Controlled Release 240, 504-526. doi:10.1016/j.jconrel.2016.06.016

Des Rieux, A., Fievez, V., Garinot, M., Schneider, Y.-J., and Préat, V. (2006). Nanoparticles as Potential Oral Delivery Systems of Proteins and Vaccines: a Mechanistic Approach. J. Controlled Release 116, 1-27. doi:10.1016/ j.jconrel.2006.08.013

Devasahayam, S. (2019). "Nanotechnology and Nanomedicine in Market," in Characterization and Biology of Nanomaterials for Drug Delivery (Elsevier), 477-522. doi:10.1016/b978-0-12-814031-4.00017-9

Ding, Y., Tian, R., Yang, Z., Chen, J., and Lu, N. (2017). NADPH Oxidasedependent Degradation of Single-Walled Carbon Nanotubes in Macrophages. J. Mater. Sci. Mater. Med. 28, 7. doi:10.1007/s10856-016-5817-z

Doogue, M. P., and Polasek, T. M. (2013). The ABCD of Clinical Pharmacokinetics. Ther. Adv. Drug Saf. 4, 5-7. doi:10.1177/2042098612469335

Döring, B., and Petzinger, E. (2014). Phase 0 and Phase III Transport in Various Organs: Combined Concept of Phases in Xenobiotic Transport and Metabolism. Drug Metab. Rev. 46, 261-282. doi:10.3109/03602532.2014.882353

Egorova, K. S., and Ananikov, V. P. (2017). Toxicity of Metal Compounds: Knowledge and Myths. Organometallics 36, 4071-4090. doi:10.1021/ acs.organomet.7b00605

Elliott, R. A. (2006). Problems with Medication Use in the Elderly: An Australian Perspective. J. Pharm. Pract. Res. 36, 58-66. doi:10.1002/j.20552335.2006.tb00889.x

Elvevold, K., Simon-Santamaria, J., Hasvold, H., Mccourt, P., Smedsrød, B., and Sørensen, K. K. (2008). Liver Sinusoidal Endothelial Cells Depend on Mannose Receptor-Mediated Recruitment of Lysosomal Enzymes for normal Degradation Capacity. Hepatology 48, 2007-2015. doi:10.1002/hep.22527

Faria, B., Gaya Da Costa, M., Poppelaars, F., Franssen, C. F. M., Pestana, M., Berger, S. P., et al. (2019). Administration of Intravenous Iron Formulations Induces Complement Activation In-Vivo. Front. Immunol. 10, 1885. doi:10.3389/ fimmu.2019.01885

Faria, M., Björnmalm, M., Thurecht, K. J., Kent, S. J., Parton, R. G., Kavallaris, M., et al. (2018). Minimum Information Reporting in Bio-Nano Experimental Literature. Nat. Nanotech 13, 777-785. doi:10.1038/s41565-018-0246-4

Fliser, D., Wagner, K.-K., Loos, A., Tsikas, D., and Haller, H. (2005). Chronic Angiotensin II Receptor Blockade Reduces (Intra)renal Vascular Resistance in Patients with Type 2 Diabetes. Jasn 16, 1135-1140. doi:10.1681/asn.2004100852

Fu, Z. D., Csanaky, I. L., and Klaassen, C. D. (2012). Effects of Aging on mRNA Profiles for Drug-Metabolizing Enzymes and Transporters in Livers of Male and Female Mice. Drug Metab. Dispos 40, 1216-1225. doi:10.1124/ dmd.111.044461

Ganesan, L. P., Mohanty, S., Kim, J., Clark, K. R., Robinson, J. M., and Anderson, C. L. (2011). Rapid and Efficient Clearance of Blood-Borne Virus by Liver Sinusoidal Endothelium. Plos Pathog. 7, e1002281. doi:10.1371/ journal.ppat.1002281
García-Álvarez, R., Hadjidemetriou, M., Sánchez-Iglesias, A., Liz-Marzán, L. M., and Kostarelos, K. (2018). In Vivo formation of Protein corona on Gold Nanoparticles. The Effect of Their Size and Shape. Nanoscale 10, 1256-1264. doi:10.1039/c7nr08322j

Gaya Da Costa, M., Poppelaars, F., Van Kooten, C., Mollnes, T. E., Tedesco, F., Würzner, R., et al. (2018). Age and Sex-Associated Changes of Complement Activity and Complement Levels in a Healthy Caucasian Population. Front. Immunol. 9, 2664. doi:10.3389/fimmu.2018.02664

Grozio, A., Mills, K. F., Yoshino, J., Bruzzone, S., Sociali, G., Tokizane, K., et al. (2019). Slc12a8 Is a Nicotinamide Mononucleotide Transporter. Nat. Metab. 1, 47-57. doi:10.1038/s42255-018-0009-4

Gudelj, I., Lauc, G., and Pezer, M. (2018). Immunoglobulin G Glycosylation in Aging and Diseases. Cell Immunol. 333, 65-79. doi:10.1016/ j.cellimm.2018.07.009

Halamoda-Kenzaoui, B., Vandebriel, R., Howarth, A., Siccardi, M., David, C. Liptrott, N., et al. (2021). Methodological Needs in the Quality and Safety Characterisation of Nanotechnology-Based Health Products: Priorities for Method Development and Standardisation. J. Control. Release 336, 192-206. doi:10.1016/j.jconrel.2021.06.016

Harrison, R. K. (2016). Phase II and Phase III Failures: 2013-2015. Nat. Rev. Drug Discov. 15, 817-818. doi:10.1038/nrd.2016.184

He, H., Liu, L., Morin, E. E., Liu, M., and Schwendeman, A. (2019). Survey of Clinical Translation of Cancer Nanomedicines-Lessons Learned from Successes and Failures. Acc. Chem. Res. 52, 2445-2461. doi:10.1021/acs.accounts.9b00228

Heise, T., Hövelmann, U., Zijlstra, E., Stender-Petersen, K., Jacobsen, J. B., and Haahr, H. (2017). A Comparison of Pharmacokinetic and Pharmacodynamic Properties between Faster-Acting Insulin Aspart and Insulin Aspart in Elderly Subjects with Type 1 Diabetes Mellitus. Drugs Aging 34, 29-38. doi:10.1007/ s40266-016-0418-6

Helmy, K. Y., Katschke, K. J., Jr, Gorgani, N. N., Kljavin, N. M., Elliott, J. M., Diehl, L., et al. (2006). CRIg: a Macrophage Complement Receptor Required for Phagocytosis of Circulating Pathogens. Cell 124, 915-927. doi:10.1016/ j.cell.2005.12.039

Hilmer, S. N. (2008). ADME-tox Issues for the Elderly. Expert Opin. Drug Metab. Toxicol. 4, 1321-1331. doi:10.1517/17425255.4.10.1321

Hilmer, S. N., Wu, H., and Zhang, M. (2019). Biology of Frailty: Implications for Clinical Pharmacology and Drug Therapy in Frail Older People. Mech. Ageing Dev. 181, 22-28. doi:10.1016/j.mad.2019.111119

Holt, P. R. (2007). Intestinal Malabsorption in the Elderly. Dig. Dis. 25, 144-150. doi:10.1159/000099479

Hou, W.-Y., Xu, S.-F., Zhu, Q.-N., Lu, Y.-F., Cheng, X.-G., and Liu, J. (2014). Ageand Sex-Related Differences of Organic Anion-Transporting Polypeptide Gene Expression in Livers of Rats. Toxicol. Appl. Pharmacol. 280, 370-377. doi:10.1016/j.taap.2014.08.020

Hunt, N. J., Kang, S. W., Lockwood, G. P., Le Couteur, D. G., and Cogger, V. C. (2019). Hallmarks of Aging in the Liver. Comput. Struct. Biotechnol. J. 17, 1151-1161. doi:10.1016/j.csbj.2019.07.021

Hunt, N. J., Lockwood, G. P., Kang, S. W. S., Westwood, L. J., Limantoro, C., Chrzanowski, W., et al. (2021). Quantum Dot Nanomedicine Formulations Dramatically Improve Pharmacological Properties and Alter Uptake Pathways of Metformin and Nicotinamide Mononucleotide in Aging Mice. ACS Nano 15, 4710-4727. doi:10.1021/acsnano.0c09278

Hunt, N. J., Lockwood, G. P., Le Couteur, F. H., Mccourt, P. A. G., Singla, N., Kang, S. W. S., et al. (2020). Rapid Intestinal Uptake and Targeted Delivery to the Liver Endothelium Using Orally Administered Silver Sulfide Quantum Dots. ACS Nano 14, 1492-1507. doi:10.1021/acsnano.9b06071

Hunt, N. J., Mccourt, P. A. G., Le Couteur, D. G., and Cogger, V. C. (2018). Novel Targets for Delaying Aging: The Importance of the Liver and Advances in Drug Delivery. Adv. Drug Deliv. Rev. 135, 39-49. doi:10.1016/j.addr.2018.09.006

Ibrahim, D., Froberg, B., Wolf, A., and Rusyniak, D. E. (2006). Heavy Metal Poisoning: Clinical Presentations and Pathophysiology. Clin. Lab. Med. 26, 67-97. doi:10.1016/j.cll.2006.02.003

Imai, S., Morishita, Y., Hata, T., Kondoh, M., Yagi, K., Gao, J.-Q., et al. (2017). Cellular Internalization, Transcellular Transport, and Cellular Effects of Silver Nanoparticles in Polarized Caco-2 Cells Following Apical or Basolateral Exposure. Biochem. Biophysical Res. Commun. 484, 543-549. doi:10.1016/ j.bbrc.2017.01.114 
Israili, Z. H., and Dayton, P. G. (2001). Human Alpha-1-Glycoprotein and its Interactions with Drugs †, 100104402

Jang, K., Chung, H., Yoon, J.-s., Moon, S.-J., Yoon, S. H., Yu, K.-S., et al. (2016). Pharmacokinetics, Safety, and Tolerability of Metformin in Healthy Elderly Subjects. J. Clin. Pharmacol. 56, 1104-1110. doi:10.1002/jcph.699

Javitt, N. B. (2014). History of Hepatic Bile Formation: Old Problems, New Approaches. Adv. Physiol. Edu. 38, 279-285. doi:10.1152/ advan.00076.2014

Jetter, A., and Kullak-Ublick, G. A. (2020). Drugs and Hepatic Transporters: A Review. Pharmacol. Res. 154, 104234. doi:10.1016/j.phrs.2019.04.018

Jourova, L., Anzenbacher, P., and Anzenbacherova, E. (2016). Human Gut Microbiota Plays a Role in the Metabolism of Drugs. Biomed. Pap. 160, 317-326. doi:10.5507/bp.2016.039

Kameyama, A., Thet Tin, W. W., Nishijima, R., and Yamakoshi, K. (2021). Alteration of Mucins in the Submandibular Gland during Aging in Mice. Arch. Oral Biol. 121, 104967. doi:10.1016/j.archoralbio.2020.104967

Ke, P. C., Lin, S., Parak, W. J., Davis, T. P., and Caruso, F. (2017). A Decade of the Protein corona. ACS Nano 11, 11773-11776. doi:10.1021/acsnano.7b08008

Khan, M. S., and Roberts, M. S. (2018). Challenges and Innovations of Drug Delivery in Older Age. Adv. Drug Deliv. Rev. 135, 3-38. doi:10.1016/ j.addr.2018.09.003

Khatun, Z., Nurunnabi, M., Reeck, G. R., Cho, K. J., and Lee, Y.-K. (2013). Oral Delivery of Taurocholic Acid Linked Heparin-Docetaxel Conjugates for Cancer Therapy. J. Controlled Release 170, 74-82. doi:10.1016/ j.jconrel.2013.04.024

Khurana, A., Allawadhi, P., Khurana, I., Allwadhi, S., Weiskirchen, R., Banothu, A. K., et al. (2021). Role of Nanotechnology behind the success of mRNA Vaccines for COVID-19. Nano Today 38, 101142. doi:10.1016/j.nantod.2021.101142

Kim, S. K., Lee, D. Y., Lee, E., Lee, Y.-K., Kim, C. Y., Moon, H. T., et al. (2007). Absorption Study of Deoxycholic Acid-Heparin Conjugate as a New Form of Oral Anti-coagulant. J. Controlled Release 120, 4-10. doi:10.1016/ j.jconrel.2007.03.008

Kishimoto, T., and Tavassoli, M. (1987). Transendothelial Transport (Transcytosis) of Iron-Transferrin Complex in the Rat Liver. Am. J. Anat. 178, 241-249. doi:10.1002/aja.1001780305

Kitchens, K. M., Foraker, A. B., Kolhatkar, R. B., Swaan, P. W., and Ghandehari, H. (2007). Endocytosis and Interaction of Poly (Amidoamine) Dendrimers with Caco-2 Cells. Pharm. Res. 24, 2138-2145. doi:10.1007/s11095-007-9415-0

Klotz, U. (2009). Pharmacokinetics and Drug Metabolism in the Elderly. Drug Metab. Rev. 41, 67-76. doi:10.1080/03602530902722679

Kolosnjaj-Tabi, J., Javed, Y., Lartigue, L., Volatron, J., Elgrabli, D., Marangon, I., et al. (2015). The One Year Fate of Iron Oxide Coated Gold Nanoparticles in Mice. ACS Nano 9, 7925-7939. doi:10.1021/acsnano.5b00042

Kothari, A., and Rajagopalan, P. (2019). Isolating Rat Intestinal Explants for In Vitro Cultures. Curr. Protoc. Toxicol. 80, e79. doi:10.1002/cptx.79

Kou, L., Bhutia, Y. D., Yao, Q., He, Z., Sun, J., and Ganapathy, V. (2018). Transporter-Guided Delivery of Nanoparticles to Improve Drug Permeation across Cellular Barriers and Drug Exposure to Selective Cell Types. Front. Pharmacol. 9, 27. doi:10.3389/fphar.2018.00027

La-Beck, N. M., Islam, M. R., and Markiewski, M. M. (2021). Nanoparticle-Induced Complement Activation: Implications for Cancer Nanomedicine. Front. Immunol. 11, 603039. doi:10.3389/fimmu.2020.603039

Le Couteur, D. G., Fraser, R., Cogger, V. C., and Mclean, A. J. (2002). Hepatic Pseudocapillarisation and Atherosclerosis in Ageing. The Lancet 359, 1612-1615. doi:10.1016/s0140-6736(02)08524-0

Le Couteur, D. G., Warren, A., Cogger, V. C., Smedsrød, B., Sørensen, K. K., De Cabo, R., et al. (2008). Old Age and the Hepatic Sinusoid. Anat. Rec. 291, 672-683. doi:10.1002/ar.20661

Lee, S., Lee, J., Lee, D. Y., Kim, S. K., Lee, Y., and Byun, Y. (2005). A New Drug Carrier, N?-deoxycholyl-l-lysyl-methylester, for Enhancing Insulin Absorption in the Intestine. Diabetologia 48, 405-411. doi:10.1007/s00125-004-1658-2

Lee, Y.-k., Kim, S. K., Lee, D. Y., Lee, S., Kim, C.-Y., Shin, H.-C., et al. (2006). Efficacy of Orally Active Chemical Conjugate of Low Molecular Weight Heparin and Deoxycholic Acid in Rats, Mice and Monkeys. J. Controlled Release 111, 290-298. doi:10.1016/j.jconrel.2005.12.011

Lee, Y.-K., Nam, J. H., Shin, H.-C., and Byun, Y. (2001). Conjugation of LowMolecular-Weight Heparin and Deoxycholic Acid for the Development of a
New Oral Anticoagulant Agent. Circulation 104, 3116-3120. doi:10.1161/ hc5001.100627

Li, H.-H., Li, J., Wasserloos, K. J., Wallace, C., Sullivan, M. G., Bauer, P. M., et al. (2013). Caveolae-Dependent and -Independent Uptake of Albumin in Cultured Rodent Pulmonary Endothelial Cells. PLoS One 8, e81903. doi:10.1371/ journal.pone.0081903

Liu, J., Chen, Q., Zhu, W., Yi, X., Yang, Y., Dong, Z., et al. (2017). NanoscaleCoordination-Polymer-Shelled Manganese Dioxide Composite Nanoparticles: A Multistage Redox/pH/H2O2-Responsive Cancer Theranostic Nanoplatform. Adv. Funct. Mater. 27, 1605926. doi:10.1002/adfm.201605926

Lyseng-Williamson, K. A., and Keating, G. M. (2009). Ferric Carboxymaltose. Drugs 69, 739-756. doi:10.2165/00003495-200969060-00007

Madathiparambil Visalakshan, R., González García, L. E., Benzigar, M. R., Ghazaryan, A., Simon, J., Mierczynska-Vasilev, A., et al. (2020). The Influence of Nanoparticle Shape on Protein corona Formation. Small 16, 2000285. doi:10.1002/smll.202000285

Mäkivuokko, H., Tiihonen, K., Tynkkynen, S., Paulin, L., and Rautonen, N. (2009). The Effect of Age and Non-steroidal Anti-inflammatory Drugs on Human Intestinal Microbiota Composition. Br. J. Nutr. 103, 227-234. doi:10.1017/ s0007114509991553

Malaviya, P., Shukal, D., and Vasavada, A. R. (2019). Nanotechnology-based Drug Delivery, Metabolism and Toxicity. Curr. Drug Metab. 20, 1167-1190. doi:10.2174/1389200221666200103091753

Malovic, I., Sørensen, K. K., Elvevold, K. H., Nedredal, G. L., Paulsen, S., Erofeev, A. V., et al. (2007). The Mannose Receptor on Murine Liver Sinusoidal Liver Endothelial Cells is the Main Denatured Collagen Clearance Receptor. Hepatology 45, 1454-1461. doi:10.1002/hep.21639

Marczynski, M., Kimna, C., and Lieleg, O. (2021). Purified Mucins in Drug Delivery Research. Adv. Drug Deliv. Rev. 178, 113845. doi:10.1016/ j.addr.2021.113845

Marshansky, V., and Futai, M. (2008). The V-type H+-ATPase in Vesicular Trafficking: Targeting, Regulation and Function. Curr. Opin. Cel Biol. 20, 415-426. doi:10.1016/j.ceb.2008.03.015

Martin, C. B., Hales, C. M., Gu, Q., and Ogden, C. L. (2019). Prescription Drug Use in the United States, 2015-2016. NCHS Data Brief, 1-8.

Mccourt, P. A. G., Smedsrød, B. H., Melkko, J., and Johansson, S. (1999). Characterization of a Hyaluronan Receptor on Rat Sinusoidal Liver Endothelial Cells and its Functional Relationship to Scavenger Receptors. Hepatology 30, 1276-1286. doi:10.1002/hep.510300521

Mclean, A. J., and Le Couteur, D. G. (2004). Aging Biology and Geriatric Clinical Pharmacology. Pharmacol. Rev. 56, 163-184. doi:10.1124/pr.56.2.4

Minakami, R., and Sumimotoa, H. (2006). Phagocytosis-Coupled Activation of the Superoxide-Producing Phagocyte Oxidase, a Member of the NADPH Oxidase (Nox) Family. Int. J. Hematol. 84, 193-198. doi:10.1532/ijh97.06133

Mitchell, S. J., Huizer-Pajkos, A., Cogger, V. C., Mclachlan, A. J., Le Couteur, D. G., Jones, B., et al. (2011). Age-related Pseudocapillarization of the Liver Sinusoidal Endothelium Impairs the Hepatic Clearance of Acetaminophen in Rats. Journals Gerontol. Ser. A: Biol. Sci. Med. Sci. 66A, 400-408. doi:10.1093/ gerona/glq221

Moghimi, S. M., Hunter, A. C., and Murray, J. C. (2001). Long-circulating and Target-specific Nanoparticles: Theory to Practice. Pharmacol. Rev. 53, 283-318.

Monopoli, M. P., Åberg, C., Salvati, A., and Dawson, K. A. (2012). Biomolecular Coronas Provide the Biological Identity of Nanosized Materials. Nat. Nanotech 7, 779-786. doi:10.1038/nnano.2012.207

Mousavi, S. A., Sporstøl, M., Fladeby, C., Kjeken, R., Barois, N., and Berg, T. (2007). Receptor-mediated Endocytosis of Immune Complexes in Rat Liver Sinusoidal Endothelial Cells Is Mediated by Fc $\gamma$ RIIb2. Hepatology 46, 871-884. doi: $10.1002 /$ hep. 21748

Nauseef, W. M. (2014). Myeloperoxidase in Human Neutrophil Host Defence. Cell Microbiol 16, 1146-1155. doi:10.1111/cmi.12312

Neuberger, T., Schöpf, B., Hofmann, H., Hofmann, M., and Von Rechenberg, B. (2005). Superparamagnetic Nanoparticles for Biomedical Applications: Possibilities and Limitations of a New Drug Delivery System. J. Magnetism Magn. Mater. 293, 483-496. doi:10.1016/j.jmmm.2005.01.064

Neumann, K., Erben, U., Kruse, N., Wechsung, K., Schumann, M., Klugewitz, K., et al. (2015). Chemokine Transfer by Liver Sinusoidal Endothelial Cells Contributes to the Recruitment of CD4+ T Cells into the Murine Liver. PLoS One 10, e0123867. doi:10.1371/journal.pone.0123867 
Nguyen-Lefebvre, A. T., and Horuzsko, A. (2015). Kupffer Cell Metabolism and Function. J. Enzymol. Metab. 1, 101.

Niazi, M., Zakeri-Milani, P., Najafi Hajivar, S., Soleymani Goloujeh, M., Ghobakhlou, N., Shahbazi Mojarrad, J., et al. (2016). Nano-based Strategies to Overcome P-Glycoprotein-Mediated Drug Resistance. Expert Opin. Drug Metab. Toxicol. 12, 1021-1033. doi:10.1080/17425255.2016.1196186

Oh, J. Y., Kim, H. S., Palanikumar, L., Go, E. M., Jana, B., Park, S. A., et al. (2018). Cloaking Nanoparticles with Protein corona Shield for Targeted Drug Delivery. Nat. Commun. 9, 4548. doi:10.1038/s41467-018-06979-4

Oh, N., and Park, J.-H. (2014). Surface Chemistry of Gold Nanoparticles Mediates Their Exocytosis in Macrophages. ACS Nano 8, 6232-6241. doi:10.1021/ nn501668a

Øie, C. I., Wolfson, D. L., Yasunori, T., Dumitriu, G., Sørensen, K. K., Mccourt, P. A., et al. (2020). Liver Sinusoidal Endothelial Cells Contribute to the Uptake and Degradation of Entero Bacterial Viruses. Sci. Rep. 10, 898. doi:10.1038/s41598020-57652-0

Pandey, E., Nour, A. S., and Harris, E. N. (2020). Prominent Receptors of Liver Sinusoidal Endothelial Cells in Liver Homeostasis and Disease. Front. Physiol. 11, 873. doi:10.3389/fphys.2020.00873

Pardi, N., Tuyishime, S., Muramatsu, H., Kariko, K., Mui, B. L., Tam, Y. K., et al. (2015). Expression Kinetics of Nucleoside-Modified mRNA Delivered in Lipid Nanoparticles to Mice by Various Routes. J. Controlled Release 217, 345-351. doi:10.1016/j.jconrel.2015.08.007

Parmentier, J., Hofhaus, G., Thomas, S., Cuesta, L. C., Gropp, F., Schröder, R., et al. (2014). Improved Oral Bioavailability of Human Growth Hormone by a Combination of Liposomes Containing Bio-Enhancers and Tetraether Lipids and Omeprazole. J. Pharm. Sci. 103, 3985-3993. doi:10.1002/ jps. 24215

Patra, J. K., Das, G., Fraceto, L. F., Campos, E. V. R., Rodriguez-Torres, M. d. P., Acosta-Torres, L. S., et al. (2018). Nano Based Drug Delivery Systems: Recent Developments and Future Prospects. J. Nanobiotechnol 16, 71. doi:10.1186/ s12951-018-0392-8

Payne, G. W., and Bearden, S. E. (2006). The Microcirculation of Skeletal Muscle in Aging. Microcirculation 13, 275-277. doi:10.1080/10739680600618710

Pinheiro, W. O., Fascineli, M. L., Farias, G. R., Hillesheim Horst, F., De Andrade, L. R., Corrêa, L. H., et al. (2019). The Influence of Female Mice Age on Biodistribution and Biocompatibility of Citrate-Coated Magnetic Nanoparticles. Ijn Vol. 14, 3375-3388. doi:10.2147/ijn.s197888

Pitek, A. S., Jameson, S. A., Veliz, F. A., Shukla, S., and Steinmetz, N. F. (2016). Serum Albumin 'camouflage' of Plant Virus Based Nanoparticles Prevents Their Antibody Recognition and Enhances Pharmacokinetics. Biomaterials 89, 89-97. doi:10.1016/j.biomaterials.2016.02.032

Pomatto, L. C. D., Cline, M., Woodward, N., Pakbin, P., Sioutas, C., Morgan, T. E., et al. (2018). Aging Attenuates Redox Adaptive Homeostasis and Proteostasis in Female Mice Exposed to Traffic-Derived Nanoparticles ('vehicular Smog'). Free Radic. Biol. Med. 121, 86-97. doi:10.1016/j.freeradbiomed.2018.04.574

Poon, W., Zhang, Y.-N., Ouyang, B., Kingston, B. R., Wu, J. L. Y., Wilhelm, S., et al. (2019). Elimination Pathways of Nanoparticles. ACS Nano 13, 5785-5798. doi:10.1021/acsnano.9b01383

Press, A. T., Traeger, A., Pietsch, C., Mosig, A., Wagner, M., Clemens, M. G., et al. (2014). Cell Type-specific Delivery of Short Interfering RNAs by DyeFunctionalised Theranostic Nanoparticles. Nat. Commun. 5, 5565. doi:10.1038/ncomms6565

Reeve, E., Trenaman, S. C., Rockwood, K., and Hilmer, S. N. (2017). Pharmacokinetic and Pharmacodynamic Alterations in Older People with Dementia. Expert Opin. Drug Metab. Toxicol. 13, 651-668. doi:10.1080/ 17425255.2017.1325873

Reeve, E., Wiese, M. D., and Mangoni, A. A. (2015). Alterations in Drug Disposition in Older Adults. Expert Opin. Drug Metab. Toxicol. 11, 491-508. doi:10.1517/17425255.2015.1004310

Richtering, W., Alberg, I., and Zentel, R. (2020). Nanoparticles in the Biological Context: Surface Morphology and Protein Corona Formation. Small 16, 2002162. doi:10.1002/smll.202002162

Saffrey, M. J. (2014). Aging of the Mammalian Gastrointestinal Tract: a Complex Organ System. Age (Dordr) 36, 9603-1032. doi:10.1007/s11357-013-9603-2

Sahoo, S. K., Parveen, S., and Panda, J. J. (2007). The Present and Future of Nanotechnology in Human Health Care. Nanomedicine: Nanotechnology, Biol. Med. 3, 20-31. doi:10.1016/j.nano.2006.11.008
Saltzman, J. R., and Russell, R. M. (1998). The Aging Gut. Gastroenterol. Clin. North America 27, 309-324. doi:10.1016/s0889-8553(05)70005-4

Sanfins, E., Correia, A., B. Gunnarsson, S., Cedervall, T., and Cedervall, T. (2018). Nanoparticle Effect on Neutrophil Produced Myeloperoxidase. PLoS One 13, e0191445. doi:10.1371/journal.pone.0191445

Schimpel, C., Teubl, B., Absenger, M., Meindl, C., Fröhlich, E., Leitinger, G., et al. (2014). Development of an Advanced Intestinal In Vitro Triple Culture Permeability Model to Study Transport of Nanoparticles. Mol. Pharmaceutics 11, 808-818. doi:10.1021/mp400507g

Seo, H. J., Nam, S. H., Im, H.-J., Park, J.-Y., Lee, J. Y., Yoo, B., et al. (2015). Rapid Hepatobiliary Excretion of Micelle-Encapsulated/Radiolabeled Upconverting Nanoparticles as an Integrated Form. Sci. Rep. 5, 15685. doi:10.1038/srep15685

Shenoy, P., and Harugeri, A. (2015). Elderly Patients' Participation in Clinical Trials. Perspect. Clin. Res. 6, 184. doi:10.4103/2229-3485.167099

Shetty, S., Lalor, P. F., and Adams, D. H. (2018). Liver Sinusoidal Endothelial Cells Gatekeepers of Hepatic Immunity. Nat. Rev. Gastroenterol. Hepatol. 15, 555-567. doi:10.1038/s41575-018-0020-y

Shin, M. D., Shukla, S., Chung, Y. H., Beiss, V., Chan, S. K., Ortega-Rivera, O. A., et al. (2020). COVID-19 Vaccine Development and a Potential Nanomaterial Path Forward. Nat. Nanotechnol. 15, 646-655. doi:10.1038/s41565-020-0737-y

Simionescu, M., Popov, D., and Sima, A. (2009). Endothelial Transcytosis in Health and Disease. Cell Tissue Res 335, 27-40. doi:10.1007/s00441-008-0688-3

Simon-Santamaria, J., Malovic, I., Warren, A., Oteiza, A., Le Couteur, D., Smedsrød, B., et al. (2010). Age-related Changes in Scavenger ReceptorMediated Endocytosis in Rat Liver Sinusoidal Endothelial Cells. J. Gerontol. A. Biol. Sci. Med. Sci. 65A, 951-960. doi:10.1093/gerona/glq108

Simon-Santamaria, J., Rinaldo, C. H., Kardas, P., Li, R., Malovic, I., Elvevold, K., et al. (2014). Efficient Uptake of Blood-Borne BK and JC Polyomavirus-like Particles in Endothelial Cells of Liver Sinusoids and Renal Vasa Recta. PLoS One 9, e111762. doi:10.1371/journal.pone.0111762

Sindhwani, S., and Chan, W. C. W. (2021). Nanotechnology for Modern Medicine: Next Step towards Clinical Translation. J. Intern. Med. 290, 486-498. doi:10.1111/joim.13254

Singh, T., and Newman, A. B. (2011). Inflammatory Markers in Population Studies of Aging. Ageing Res. Rev. 10, 319-329. doi:10.1016/j.arr.2010.11.002

Sørensen, K. K., Mccourt, P., Berg, T., Crossley, C., Le Couteur, D., Wake, K., et al. (2012). The Scavenger Endothelial Cell: a New Player in Homeostasis and Immunity. Am. J. Physiol. Regul. Integr. Comp. Physiol. 303, R1217-R1230. doi:10.1152/ajpregu.00686.2011

Souris, J. S., Lee, C.-H., Cheng, S.-H., Chen, C.-T., Yang, C.-S., Ho, J.-a. A., et al. (2010). Surface Charge-Mediated Rapid Hepatobiliary Excretion of Mesoporous Silica Nanoparticles. Biomaterials 31, 5564-5574. doi:10.1016/ j.biomaterials.2010.03.048

Suk, J. S., Xu, Q., Kim, N., Hanes, J., and Ensign, L. M. (2016). PEGylation as a Strategy for Improving Nanoparticle-Based Drug and Gene Delivery. Adv. Drug Deliv. Rev. 99, 28-51. doi:10.1016/j.addr.2015.09.012

Tenzer, S., Docter, D., Kuharev, J., Musyanovych, A., Fetz, V., Hecht, R., et al. (2013). Rapid Formation of Plasma Protein corona Critically Affects Nanoparticle Pathophysiology. Nat. Nanotech 8, 772-781. doi:10.1038/ nnano.2013.181

Tsoi, K. M., Macparland, S. A., Ma, X.-Z., Spetzler, V. N., Echeverri, J., Ouyang, B., et al. (2016). Mechanism of Hard-Nanomaterial Clearance by the Liver. Nat. Mater 15, 1212-1221. doi:10.1038/nmat4718

Tyagi, P., Pechenov, S., and Anand Subramony, J. (2018). Oral Peptide Delivery: Translational Challenges Due to Physiological Effects. J. Controlled Release 287, 167-176. doi:10.1016/j.jconrel.2018.08.032

Ueno, Y., Futagawa, H., Takagi, Y., Ueno, A., and Mizushima, Y. (2005). Drugincorporating Calcium Carbonate Nanoparticles for a New Delivery System. J. Controlled Release 103, 93-98. doi:10.1016/j.jconrel.2004.11.015

Uribe-Querol, E., and Rosales, C. (2020). Phagocytosis: Our Current Understanding of a Universal Biological Process. Front. Immunol. 11, 1066. doi:10.3389/fimmu.2020.01066

Vinarov, Z., Abrahamsson, B., Artursson, P., Batchelor, H., Berben, P., BernkopSchnürch, A., et al. (2021). Current Challenges and Future Perspectives in Oral Absorption Research: An Opinion of the UNGAP Network. Adv. Drug Deliv. Rev. 171, 289-331. doi:10.1016/j.addr.2021.02.001

Vu, V. P., Gifford, G. B., Chen, F., Benasutti, H., Wang, G., Groman, E. V., et al. (2019). Immunoglobulin Deposition on Biomolecule corona Determines 
Complement Opsonization Efficiency of Preclinical and Clinical Nanoparticles. Nat. Nanotechnol. 14, 260-268. doi:10.1038/s41565-018-0344-3

Walkey, C. D., Olsen, J. B., Guo, H., Emili, A., and Chan, W. C. W. (2012). Nanoparticle Size and Surface Chemistry Determine Serum Protein Adsorption and Macrophage Uptake. J. Am. Chem. Soc. 134, 2139-2147. doi:10.1021/ja2084338

Walrath, T., Dyamenahalli, K. U., Hulsebus, H. J., Mccullough, R. L., Idrovo, J. P., Boe, D. M., et al. (2021). Age-related Changes in Intestinal Immunity and the Microbiome. J. Leukoc. Biol. 109, 1045-1061. doi:10.1002/jlb.3ri0620-405rr

Warrington, J. S., Greenblatt, D. J., and Von Moltke, L. L. (2004). The Effect of Age on P-Glycoprotein Expression and Function in the Fischer-344 Rat. J. Pharmacol. Exp. Ther. 309, 730-736. doi:10.1124/jpet.103.061234

Weitzmann, M. N., Ha, S.-W., Vikulina, T., Roser-Page, S., Lee, J.-K., and Beck, G. R. (2015). Bioactive Silica Nanoparticles Reverse Age-Associated Bone Loss in Mice. Nanomedicine: Nanotechnology, Biol. Med. 11, 959-967. doi:10.1016/j.nano.2015.01.013

Wu, K.-C., and Lin, C.-J. (2019). The Regulation of Drug-Metabolizing Enzymes and Membrane Transporters by Inflammation: Evidences in Inflammatory Diseases and Age-Related Disorders. J. Food Drug Anal. 27, 48-59. doi:10.1016/ j.jfda.2018.11.005

Xu, Y.-J., Wang, Y., Lu, Y.-F., Xu, S.-F., Wu, Q., and Liu, J. (2017). Age-associated Differences in Transporter Gene Expression in Kidneys of Male Rats. Mol. Med. Rep. 15, 474-482. doi:10.3892/mmr.2016.5970

Yao, M., He, L., Mcclements, D. J., and Xiao, H. (2015). Uptake of Gold Nanoparticles by Intestinal Epithelial Cells: Impact of Particle Size on Their Absorption, Accumulation, and Toxicity. J. Agric. Food Chem. 63, 8044-8049. doi:10.1021/acs.jafc.5b03242

Yin, J., and Wang, J. (2016). Renal Drug Transporters and Their Significance in Drug-Drug Interactions. Acta Pharmaceutica Sinica B 6, 363-373. doi:10.1016/ j.apsb.2016.07.013

Yong, S.-B., Song, Y., Kim, H. J., Ain, Q. U., and Kim, Y.-H. (2017). Mononuclear Phagocytes as a Target, Not a Barrier, for Drug Delivery. J. Controlled Release 259, 53-61. doi:10.1016/j.jconrel.2017.01.024

Yoo, J.-W., Chambers, E., and Mitragotri, S. (2010). Factors that Control the Circulation Time of Nanoparticles in Blood: Challenges, Solutions and Future Prospects. Cpd 16, 2298-2307. doi:10.2174/138161210791920496

Yuasa, H., Soga, N., Kimura, Y., and Watanabe, J. (1997). Effect of Aging on the Intestinal Transport of Hydrophilic Drugs in the Rat Small Intestine. Biol. Pharm. Bull. 20, 1188-1192. doi:10.1248/bpb.20.1188
Zhang, H., Liu, H., Davies, K. J. A., Sioutas, C., Finch, C. E., Morgan, T. E., et al. (2012). Nrf2-regulated Phase II Enzymes Are Induced by Chronic Ambient Nanoparticle Exposure in Young Mice with Age-Related Impairments. Free Radic. Biol. Med. 52, 2038-2046. doi:10.1016/j.freeradbiomed.2012.02.042

Zhang, X., Qi, J., Lu, Y., He, W., Li, X., and Wu, W. (2014). Biotinylated Liposomes as Potential Carriers for the Oral Delivery of Insulin. Nanomedicine: Nanotechnology, Biol. Med. 10, 167-176. doi:10.1016/j.nano.2013.07.011

Zhang, Y.-N., Poon, W., Tavares, A. J., Mcgilvray, I. D., and Chan, W. C. W. (2016). Nanoparticle-liver Interactions: Cellular Uptake and Hepatobiliary Elimination. J. Controlled Release 240, 332-348. doi:10.1016/ j.jconrel.2016.01.020

Zhang, Z., Li, H., Xu, G., and Yao, P. (2018). Liver-targeted Delivery of InsulinLoaded Nanoparticles via Enterohepatic Circulation of Bile Acids. Drug Deliv. 25, 1224-1233. doi:10.1080/10717544.2018.1469685

Zolnik, B. S., and Sadrieh, N. (2009). Regulatory Perspective on the Importance of ADME Assessment of Nanoscale Material Containing Drugs. Adv. Drug Deliv. Rev. 61, 422-427. doi:10.1016/ j.addr.2009.03.006

Conflict of Interest: The authors declare that the research was conducted in the absence of any commercial or financial relationships that could be construed as a potential conflict of interest.

Publisher's Note: All claims expressed in this article are solely those of the authors and do not necessarily represent those of their affiliated organizations, or those of the publisher, the editors and the reviewers. Any product that may be evaluated in this article, or claim that may be made by its manufacturer, is not guaranteed or endorsed by the publisher.

Copyright $\odot 2022$ Hunt, McCourt, Kuncic, Le Couteur and Cogger. This is an openaccess article distributed under the terms of the Creative Commons Attribution License (CC BY). The use, distribution or reproduction in other forums is permitted, provided the original author(s) and the copyright owner(s) are credited and that the original publication in this journal is cited, in accordance with accepted academic practice. No use, distribution or reproduction is permitted which does not comply with these terms. 